"The Farmer, the Blue-collar, and the Monk: Understanding economic development through saturations of demands and non-homothetic productivity gains"

Elie Gray, André Grimaud, David Le Bris 


\title{
The Farmer, the Blue-collar, and the Monk: Understanding economic development through saturations of demands and non-homothetic productivity gains
}

\author{
Elie Gray*, André Grimaud ${ }^{\dagger}$, David Le Bris ${ }^{\ddagger}$ \\ Working Paper - This draft: March 6, 2018
}

\begin{abstract}
To explain the process of development historically documented, we consider a model with three economic sectors (agriculture, manufacturing and services) characterized by different productivity gains and by saturation levels in the demands of agricultural and manufactured goods. Our parsimonious model captures within a single framework the process of development which is characterized by the structural changes in the workforce across sectors, variable growth rates (an initial "Malthusian regime" exhibiting slow growth, a fast growth regime after a takeoff, and a gradual slow down leading to a possible new stagnation) and the relative evolutions of prices across sectors. Reasonable calibration generates results quantitatively close to the observed empirical facts.
\end{abstract}

Keywords: Growth model - Structural change - Unified growth - Economic development - Saturation of demands

JEL Classification: O1, O4, N1

\section{Introduction}

There is a consensus on three major stylized facts characterizing the process of development. First, a gradual reallocation of the labor force from agriculture to services interspaced by a temporary but important shift in manufacturing. Second, a long period of weak growth turning suddenly into a period of very high growth, before rapidly slowing down again (and maybe heading towards a stagnation). Third, a fall in the prices of agricultural and manufactured products compared to the prices of services. Well documented by economic historians, these facts remain complicated to explain jointly by economic theory. Inspired by the model of economic development proposed by Fourastié (1949), we develop in this paper a simple framework which reproduces these three stylized facts. ${ }^{1}$ This theoretical growth model considers three sectors (Agriculture, Manufacturing and Services), each of which produces an homogenous good and experiences specific (exogenous) productivity gains, and a representative household whose key characteristic lies in the occurrence of saturation in the demands of agricultural and of manufactured goods.

Our parsimonious model is based on two crucial assumptions; the first one relates to the representative household and the second one to the productivity gains experienced by the producers of the three consumption goods. The first assumption is that human being is characterized by saturations in the demands of agricultural and manufactured goods; a human being do not eat more and more in proportion of his revenue (Engel curve) and the same phenomena exists for manufactured products (no one needs ten washing machines or cars); Boppart (2014) provides evidence of a decline of the share of these goods in total expenditure. The second assumption is

\footnotetext{
*Université de Toulouse, Toulouse Business School. 20 Bd. Lascrosses, BP 701031068 Toulouse Cedex 7, France. Tel.: +33 (0)5.61.29.49.25 . Email: e.gray@tbs-education.fr.

${ }^{\dagger}$ Université de Toulouse, Toulouse School of Economics. Email: andre.grimaud@tse-fr.eu.

$\ddagger$ Université de Toulouse, Toulouse Business School. 20 Bd. Lascrosses, BP 701031068 Toulouse Cedex 7, France. Tel.: +33 (0)5.61.29.49.94 . Email: d.le-bris@tbs-education.fr.

${ }^{1}$ About Fourastié (1949) see Alcouffe \& Le Bris (2016).
} 
that productivity gains (resulting from accumulation of human capital, physical capital and knowledge) are non-homothetic across the three sectors. In particular, the productivity gains are much higher in manufacturing than in services. For instance, there is more productivity gains in the manufacturing of a light bulb than in realizing a haircut. Agriculture experiences gains in between these two extremes.

From this dynamic general equilibrium model, we derive the paths of all quantities (levels of per capita consumptions of each of the three goods, as well as the labor partition across the three sectors) and of all prices (relative prices in terms of the wage). Based on these two key assumptions the model replicates accurately the three stylised facts. The formal results of our model distinguish three different phases in the process of development. Not only the theoretical curves have the same general patterns as the observed trajectories, but if we calibrate the parameters of our model using somehow realistic values, we obtain quantitative results that match well empirical observations. To run this quantitative exercise, we rely on economic history to retain sensible values for each parameter of the model. We start running our calibrated model in year 1450 when an era of stability occurred with the end of the Hundred Years' war.

The first stylized fact reproduced is the structural changes in the partition of labor across sectors. A first phase is characterized by a stable partition of labor across the three sectors; during this phase, the weak but positive growth in agricultural productivity implies that saturation in agricultural products is reached around 1800 . In a second phase, additional productivity gains lead to a reallocation of labor from agriculture into manufacturing and services basically because people do not want to consume more and more agricultural products. The production of manufactured goods increases quickly up to its saturation point, which is reached about 150 years later. Finally, in a third phase, the services sector becomes the only one for which demand is not saturated. Besides, as the saturation thresholds in agriculture and manufacturing have been reached, the productivity gains in these two sectors reduce the required labor force, which gradually reallocates in services during this third phase.

The second stylized fact reproduced by our quantitative exercise is the pattern of economic growth. The GDP grow rate remained low during the first phase, basically because the main share of the labor force is in the agriculture, sector characterized by medium productivity gains. This is consistent with reality as recent studies reject the previous view of a purely stagnationist "Malthusian epoch". After agricultural saturation is reached, economic growth intensifies because more workers are employed in manufacturing, the sector that experiences the strongest productivity gains. Thanks to this mass of workers enjoying the higher productivity gains, the growth rate quickly records a maximum. The period surrounding this peak of employment in manufacturing corresponds to the "Thirty Glorious Years", as named by Fourastie (1979). Once the demand for manufactured products reaches its saturation level, the growth rate declines because of an increasing share of the labor force work in services, the sector that exhibits the lowest productivity gains.

Finally, our quantitative exercise enables us to reproduce a third stylized fact, as we show a clear decline of the three real prices (in terms of the wage). Besides, we show that, as suggested by empirical studies, the sector in which the price experiences the fastest decrease is manufacturing, then comes agriculture, and services.

Our model offers an original way to capture the process of development, and in particular the drastic structural changes across economic sectors. As argued in the very comprehensive state of the literature on growth and structural transformation by Herrendorf et al. (2014), two main forces behind the reallocation of production factors across agriculture, manufacturing and services can be identified: technological-driven and preferences-driven. Accordingly, two ranges of literature have been developed to assess these transformations, each of which trying to understand structural changes through mechanisms involving either the supply-side or the demand-side.

Within supply-side theories, two approaches can be distinguished (see Herrendorf et al., 2015). A first one consists in considering various sectors, each of which experiencing specific productivity gains. It puts the heterogeneity of technical progress across sectors at the center of the analysis of structural change, often by using Cobb-Douglas sectoral production functions with equal exponents and which differ only in technical progress. ${ }^{2}$ Inspired by Fourastié (1949), the famous article of Baumol (1967) introduces the concept of an economy with two sectors diverging in terms of

\footnotetext{
${ }^{2}$ This approach has the advantage of tractability: "under the additional assumptions of perfect competition and profit maximization, the exponent on capital equals the share of capital in aggregate income[...], which is easily calculated" (Herrendorf et al., 2015). However, it consider only on the part played by technical progress in structural transformation.
} 
productivity gains. Following this path, Ngai \& Pissarides (2007) consider differentiated rates of technological progress among multiple sectors; then structural change is generated by changes in relative prices. Complementarily, Acemoglu \& Guerrieri (2008) underline that structural change can also be the result of sectoral differences in the capital intensity which imply that technological change goes along with an increase in the capital-to-labor ratio.

Alternatively, demand-side theories put forward the part played by non homothetic preferences (in order to introduce some heterogeneity in income elasticities of demand across sectors) in structural changes. Various forms of utility functions have been considered. ${ }^{3}$ In particular, in Kongsamut et al. (2001), productivity gains are uniform across sectors and all structural change is driven by income effects that are generated by Stone-Geary preferences. The use of the StoneGeary utility function allows the existence of a subsistence level of consumption of the agricultural good that must be achieved by the household. Only once this minimum level is reached, the household may begin to consume other goods. Accordingly, this type of preferences makes possible to formalize structural change. Besides, assessing the importance of the preferences in the process of structural change using post-1947 U.S. data, Herrendorf et al. (2013) show that the utility function used by Kongsamut et al. (2001) provides a good fit to the data. However, Stone-Geary preferences present a major drawback: for sufficiently low levels of income, the consumption of services and thus the share of labor in services may be nil.

Boppart (2014) reconciles the two forces of structural changes hereinbefore mentioned. On the demand side, he uses a type of price-independent generalized-linear (PIGL) preferences which generates reallocation of labor across sectors over time while avoiding the drawback involved by Stone-Geary preferences. He combine it with sector-specific productivity gains on the supply-side. Yet, as argued by Comin et al. (2015), this specification can "only accommodate two goods with distinct income elasticities". Comin et al. (2015) extend this approach to an arbitrary number of goods and furthermore introduces heterogeneous productivity gains as in Ngai \& Pissarides (2007). The resulting framework reproduces well structural changes by considering both long-run demand and supply drivers. Likewise, our model builds both on demand and on supply sources of structural changes. As in most supply-side theories, we consider three sectors that experience different productivity gains. Besides, we use an original approach to formalize non homothetic preferences which appear to be more consistent with historical facts: our assumption of saturations in the demands of agricultural and manufactured goods does not prevent the fact that the household consumes the three goods from the beginning (unlike the Stone-Geary specification in which the household start to consume other goods only after reaching the subsistence level). ${ }^{4}$

The hereinbefore mentioned models capture the structural changes historically documented, but they are not able to explain the changes in the growth trends in the long run (especially, they do not explain the economic take-off). More generally, most of the growth models are unable to generate within a single framework the slow growth observed for centuries, the economic take-off and the decreasing growth we observe for a few decades. Malthusian models reproduce the growth process during the Malthusian epoch, but are not able to explain the transition to the economic take-off. Standard growth models relying on exogenous technological change (e.g. Solow, 1956) or relying on endogenous technological change (e.g. Romer, 1990; Grossman \& Helpman, 1991; Aghion \& Howitt, 1992) reproduce accurately the growth process of the developed economies. However, they are not able to generate neither the origin of the take-off nor the recent decrease in growth rates.

Other models have been proposed to capture the process of the economic development as a whole. For instance, Hansen \& Prescott (2002) explain the economic transition by a technological exogenous progress making manufacturing productive enough to attract resources from agriculture. The most exhaustive work on the matter is the Unified Growth Theory (Galor, 2005), in which the process of development is explained in the light of demography and investment in human capital. A larger population allows an increase in the technological progress, but with development, parents decide to reduce fertility to privilege quality of children required to fit in a more technologically advanced economy. The trigger mechanism thus consists in reaching a critical size of population, whereas in our model, the take-off occurs when satiety in agricultural product is reached, that is when the cumulated productivity gains have been sufficient. Unified Growth Theory captures well

\footnotetext{
${ }^{3}$ For instance, Matsuyama (1992), Echevarria (1997), Laitner (2000), Kongsamut et al. (2001), Gollin et al. (2002) use quasi-homothetic intra-temporal preferences; while Zweimueller (2000), Matsuyama (2002), Foellmi \& Zweimueller (2008) and Buera \& Kaboski (2012) use hierarchy of needs to consider non-homotheticity.

${ }^{4}$ This feature seems to match reality; indeed, it appears that even when suffering from starvation households consume a minimum of manufactured products (e.g. agricultural tools, culinary utensils) and of services (e.g. collective services of security).
} 
three phases of economic growth: a Malthusian stagnation, a transition and a period of strong growth. Our model also depicts several alike phases; however, it offers a better fit with data showing a first period characterized by a weak but positive growth for a long time period, then a gradual rise during the economic take-off leading to the highest growth rates in the middle of the twentieth century. Besides, our model also enables us to formalize the slowdown in growth that has been observed for a few decades. Furthermore, contrary to the UGT framework, our model does not require to consider either demographic transition or investment in human capital in order to reproduce the stylized facts. This omission is however not totaly inconsistent with historical facts. Indeed, industrialization started first in England whereas, at the same time, France pioneered the demographic transition and Germany was the leader in terms of literacy rates. One could thus argue that economic development, demographic transition and investment in human capital are three partially independent phenomena. For sure, human capital as well as other social factors play a role in the development but in our model the aggregated effect of these factors is captured by the level of productivity gains. These different productivity gains (which result from various factors stressed in the literature) explain the discrepancy in the timings of development across human communities.

In fact, when most existing models tend to consider relatively complex formalization and to study complex dynamics, our model exhibits simple mechanisms and yet still manages to reproduce accurately several major stylized facts simultaneously. Introducing differentiated productivity gains across sectors and saturations in the demands of agricultural and manufactured goods, our model depicts the structural changes in the labor force (a gradual reallocation across agriculture, manufacturing and services) as well as the changes in growth observed over time, especially the weak growth observed for centuries and the very strong growth reached in the middle of the 20th century. Therewith, it enables us to tackle a contemporary (early 21st century) issue, obviously not apprehended by older research: the declining growth rates and the beginning of a possible secular stagnation. Finally, our model also exhibits divergent evolutions of the real prices in agriculture, manufacturing and services.

Along with the principle of Occam's razor, we retain this very simple model even if more sophisticated versions (including endogenous physical capital accumulation, the use of land in the agriculture, population growth, or endogenous technical progress) could enable us to reproduce additional stylized facts. The model presented in this paper is voluntarily kept simple to emphasize the key mechanism underlying well documented stylized facts regarding the process of development.

The rest of the paper is organized as follow. Section 2 presents the three stylized facts reproduced by our model. Section 3 presents the model and the main theoretical results explaining economic changes. Section 4 exhibits the quantitative exercise. All figures are presented in the appendix.

\section{Stylized Facts}

The process of economic development has been characterized by three important stylized facts.

The first stylized fact regarding the process of economic development lies in dramatic movements in the repartition of the workforce across the main sectors of the economy. Following Fisher (1939), economic activity is often rudely divided in three important sectors: agriculture, manufacturing and services. At the end of the Middle Ages, about $70 \%$ of the labor force worked in the agriculture; for instance, $71 \%$ in France and $74 \%$ in England in 1400, according to Allen (2001). In other words, less than one third of the population worked in manufacturing and services. From this initial situation, one observes a constant decline in the share of the labor force in the agriculture: $68 \%$ in 1600, 63\% in 1700 and $60 \%$ in 1800 for the case of France (Allen, 2001); these changes started earlier in England (Wallis et al., 2017). In 1800, at the eve of the economic take-off, $22 \%$ of the population worked in manufacturing and $14 \%$ in services. One century later, in 1900 , manufacturing and services each employed $30 \%$ of the population; agriculture still employing the remaining $40 \%$. While the share of the labor force continued to decline in the agriculture, it pursued its rise in services; a peak of employment was observed in manufacturing in the middle of the 20th century. In a study made on 25 developed countries for the 20th century, Feinstein (1999) reports that each of them recorded a peak in the share of employment in manufacturing, spanning from 1955 for the UK to 1982 for Greece. Each of these peaks have reached different levels, ranging from $30.2 \%$ in Greece (observed in 1982) to $49.3 \%$ in West Germany (observed in 1970). These structural changes have been extensively documented for decades (e.g. Fourastié, 1949; Kuznets, 
1957, 1966; Chennery, 1960; Kongsamut, 2001). A recent very illustrative figure from Herrendorf et al. (2014) is reproduced in Figure 1.

\section{Fig. 1. Around here}

The second stylized fact regards the evolution of the speed of the process of economic development as measured by GDP per capita. The process of economic growth can indeed be divided in three successive phases. The longest part of the economic history often called "Malthusian epoch" was characterized by a weak but positive economic growth per capita. ${ }^{5}$ While a form of stagnation was for long hypothesized, the most recent estimations show that growth was very low but positive for centuries before the period known as the economic "take-off". Especially for agriculture, prominent historians have demonstrated that both output and productivity per capita rose significantly in the 16th and 17th centuries (Allen 1999). This observation of a growth of GDP per capita, even if limited in magnitude, is confirmed at the wage level (Humphries \& Weisdorf, 2016). Updating the Maddison project database, Bolt \& van Zanden (2014) provide accurate long run data for UK and Netherland. They document average growth rates of GDP per capita of $0.24 \%$ per year in Netherland and of $0.21 \%$ per year in England between the 14th century and 1800. In a second phase, developed countries recorded an annual increase of the GDP per capita above $1.5 \%$ between 1800 and 2000 (e.g. 1.53\% in Netherland and $1.79 \%$ in England). This phase encompasses the economic take-off characterized by industrialization as well as the short period of very high growth of the "Thirty Glorious" years. ${ }^{6}$ Regarding the potential third phase, there is a current debate about a potential secular stagnation (Teulings \& Baldwin, 2014). Indeed, the most developed countries have experienced growth rates below $1 \%$ during the last decade (e.g. Piketty, 2014; Bolt \& van Zanden, 2014). These three phases of economic development are illustrated in Figure 2 for England and Netherland (1300-2015).

\section{Fig. 2. Around here}

The third stylized fact is the historical evolution of prices in each sectors. The historical increase of the relative price of hand-made services is the famous Baumol's cost disease which "refers to the tendency of costs and prices in a number of services, notably healthcare, education, legal services and live artistic performance, to rise persistently and cumulatively faster than the rate of inflation" (Baumol, 2004). Contrarily, the prices of investments goods (which are mainly manufactured goods) exhibit a strong decline over time, as documented by Karabarbounis \& Neiman (2014). Relative prices of the agricultural products are on a well-known declining trend from the beginning of the economic take-off. As an illustration of the evolution of prices in the three sectors, Figure 3 depicts the evolution of the prices of bread, electric bulb and male haircut, expressed in number of hours of a standard worker wage (i.e. each year, the current price is divided by the current hourly wage). ${ }^{7}$ These three products are each typical of one of the three sectors and have remained similar over time. An unqualified worker could buy a $2 \mathrm{~kg}$ loaf of bread in exchange for 2.5 hours of work in 1912; today it requires only half an hour. In 1912, the price of producing one electric light bulb represented six hours of unqualified wage labor whereas the price in 2015 is no more than twelve minutes. As a typical case in the tertiary sector, a male haircut still represents more than one hour of unqualified work as it did in 1912; the relative price is about stable.

Fig. 3. Around here

\section{The Model}

There are four goods: three consumption goods and labor. Consumption goods are produced by three sectors: agriculture, manufacturing and services. Each sector produces an homogenous good. We denoted by $p_{t}^{A}$, by $p_{t}^{M}$, and by $p_{t}^{S}$, the prices at date $t$ of the agricultural good, of the manufactured good, and of the services. As it will be detailed below, these sectors are characterized by different technological growth rates; moreover, we consider saturation levels in the consumptions

\footnotetext{
${ }^{5}$ As explained by Guinnane and Ogilvie (2008), the expression "Malthusian" is used by economists to describe the economic context existing before the take-off but without assuming the theory of Malthus made of three relationships i. births depend on economic condition, ii. deaths depend on economic conditions, and iii. economic condition is a negative function of the number of people using a given stock of capital and natural resources.

${ }^{6}$ Fourastie forged this expression as the title of a book published in 1979.

${ }^{7}$ These series have been initially collected by Jean Fourastié and updated by his daughter Jacqueline Fourastié and made available on the website of the Comité Fourastié (http://stats.fourastie-sauvy.org/).
} 
of the agricultural good and of the manufactured good. Besides, at each date $t$, there are $L$ identical households, each of which is endowed with one unit of labor that is supplied inelastically; the total quantity of labor $L$ is used in the agriculture (quantity $L_{t}^{A}$ ), in manufacturing (quantity $L_{t}^{M}$ ) and in the services (quantity $L_{t}^{S}$ ). Hence, at each date $t$, the constraint on the labor market is

$$
L=L_{t}^{A}+L_{t}^{M}+L_{t}^{S}
$$

The wage is denoted by $w_{t}$. According to Walras' law, we can normalize $w_{t}$ to one.

In Section 3.1, we present the preferences and the behavior of the representative household. In particular, we introduce a utility function which exhibits saturations in the demands for agricultural and manufactured goods, and we derive the demand functions. Then, in Section 3.2, we present the technologies and the producers' behavior. Finally, the general equilibrium is characterized in Section 3.3; for each of the three phases, we derive the relative prices (in terms of the wage), and we compute the equilibrium quantities of per capita consumptions and the equilibrium labor partition.

\subsection{Preferences and consumer's behavior}

Let $a_{t}, m_{t}$, and $s_{t}$, denote the representative household's consumptions of the goods produced by the agricultural, manufacturing, and the services sectors, respectively. A key point is to allow the representative household's preferences to consider possible saturations in the demands for rival goods. The saturation levels of the demand for the agricultural good and of the demand for the manufactured good are denoted by $\bar{a}$ and by $\bar{m}$, respectively. We assume that at each date $t$ the instantaneous preferences of the representative household's are given by a Cobb-Douglas with saturations utility function: ${ }^{8}$

$$
\mathcal{U}\left(a_{t}, m_{t}, s_{t}\right)=\left(a_{t}\right)^{\alpha}\left(m_{t}\right)^{\mu}\left(s_{t}\right)^{\sigma}, \text { with } a_{t} \leq \bar{a}, m_{t} \leq \bar{m} \text { and } \alpha+\mu+\sigma=1
$$

At each date $t$, the representative household maximizes (2) subject to her budget constraint:

$$
p_{t}^{A} a_{t}+p_{t}^{M} m_{t}+p_{t}^{S} s_{t}=1\left(\equiv w_{t}\right)
$$

Let us denote by $t^{\bar{a}}$ and $t^{\bar{m}}$ the dates at which the saturation levels of the demands for agricultural and manufactured goods are reached, that is such that

$$
a_{t}=\bar{a}, \forall t \geq t^{\bar{a}} \text { and } m_{t}=\bar{m}, \forall t \geq t^{\bar{m}}
$$

According to well established stylized facts, we consider that the saturation of the demand for the agricultural good occurs before the one of the demand for the manufactured good; formally, we will focus on values of the parameters such that $t^{\bar{a}}<t^{\bar{m}}$. Given this assumption, this framework gives rise to three successive phases. In Phase I, neither the saturation level of the demand for the agricultural good, nor the one of the demand for the manufactured good have been reached $\left(t<t^{\bar{a}}\right)$. In Phase II, the saturation level of the demand for the agricultural good has been reached, while it is not the case yet for the demand for the manufactured good $\left(t^{\bar{a}} \leq t<t^{\bar{m}}\right)$. In Phase III, both saturation levels have been reached $\left(t^{\bar{m}} \leq t\right)$.

In the three following lemmas, we derive for each of these three phases the demand functions of the representative household.

Phase I - No saturations: $a_{t}<\bar{a}$ and $m_{t}<\bar{m}\left(t<t^{\bar{a}}\right)$

If no saturation level has been reached, that is if $t<t^{\bar{a}}$, the program of the representative household is

$$
\operatorname{Max} \mathcal{U}\left(a_{t}, m_{t}, s_{t}\right)=\left(a_{t}\right)^{\alpha}\left(m_{t}\right)^{\mu}\left(s_{t}\right)^{\sigma} \text { subject to } p_{t}^{A} a_{t}+p_{t}^{M} m_{t}+p_{t}^{S} s_{t}=1
$$

One obtains the following lemma.

Lemma 1. Before any saturation occurs (i.e. $\forall t$ such that $t<t^{\bar{a}}$ ), the demand functions for the agricultural good, for the manufactured good, and for services are

$$
a_{t}=\frac{\alpha}{p_{t}^{A}}, m_{t}=\frac{\mu}{p_{t}^{M}}, \text { and } s_{t}=\frac{\sigma}{p_{t}^{S}}
$$

\footnotetext{
${ }^{8}$ The assumptions retained on preferences have been chosen in order to get simple closed form solutions and, as explained above, they do not prevent us from developing a model which replicates accurately the stylized facts. In particular, we could have considered a more complex utility function to account for saturations and we could also have considered an intertemporal utility function.
} 
Because saturations have not been reached, one gets the standard demand functions resulting from a Cobb-Douglas utility function.

Phase II - Saturation in the demand for the agricultural good and no saturation in the demand for the manufactured good: $a_{t}=\bar{a}$ and $m_{t}<\bar{m}\left(t^{\bar{a}} \leq t<t^{\bar{m}}\right)$

At date $t^{\bar{a}}$, the demand for the agricultural good reaches its saturation level $\bar{a}$; then, the demand is $a_{t}=\bar{a}, \forall t \geq t^{\bar{a}}$. From this date, and as long as the demand for the manufactured good has not reached its saturation level $\bar{m}$ (i.e. $\forall t \in\left[t^{\bar{a}} ; t^{\bar{m}}[\right.$ ), the program of the representative household is

$$
\operatorname{Max} \mathcal{U}\left(\bar{a}, m_{t}, s_{t}\right)=\bar{a}^{\alpha}\left(m_{t}\right)^{\mu}\left(s_{t}\right)^{\sigma}, \text { subject to } p_{t}^{M} m_{t}+p_{t}^{S} s_{t}=1-p_{t}^{A} \bar{a}
$$

One gets the following lemma.

Lemma 2. Once the saturation level of the demand for the agricultural good has been reached, and until the saturation level of the demand for the manufactured good is reached, that is $\forall t \in\left[t^{\bar{a}} ; t^{\bar{m}}[\right.$, the demand functions for the agricultural good, for the manufactured good, and for services are

$$
a_{t}=\bar{a}, m_{t}=\frac{\mu\left(1-p_{t}^{A} \bar{a}\right)}{(\mu+\sigma) p_{t}^{M}}, \text { and } s_{t}=\frac{\sigma\left(1-p_{t}^{A} \bar{a}\right)}{(\mu+\sigma) p_{t}^{S}}
$$

In Phase II, the demands of the three goods depend not only on the revenue and on the prices (as in Phase I), but also on the saturation level $\bar{a}$.

Phase III - Saturation in the demands for agricultural and manufactured goods: $a_{t}=\bar{a}$ and $m_{t}=\bar{m}\left(t^{\bar{m}} \leq t\right)$

If $t^{\bar{m}} \leq t$, then the demand for the agricultural good and the demand for the manufactured good have both reached their saturation levels: $a_{t}=\bar{a}$ and $m_{t}=\bar{m}$. The budget constraint of the representative household then writes $p_{t}^{S} s_{t}=1-p_{t}^{A} \bar{a}-p_{t}^{M} \bar{m}$. Accordingly, one obtains the following lemma.

Lemma 3. Once the saturation levels of the demand for the agricultural good and of the demand for the manufactured good have been reached (i.e. for all $t$ such that $t^{\bar{m}} \leq t$ ), the demand functions for the agricultural good, for the manufactured good, and for services are

$$
a_{t}=\bar{a}, m_{t}=\bar{m}, \text { and } s_{t}=\frac{1-p_{t}^{A} \bar{a}-p_{t}^{M} \bar{m}}{p_{t}^{S}}
$$

In Phase III, the demands of the three goods now depend on the revenue, on the prices, and on the two saturation levels $\bar{a}$ and $\bar{m}$.

\subsection{Technologies and producers' behavior}

The production of the agricultural good, of the manufactured good and of services requires the use of labor (in quantities $L_{t}^{A}, L_{t}^{M}$ and $L_{t}^{S}$, respectively). Besides, each of the three sectors is characterized by its own productivity level $\chi_{t}^{X}(X=A, M, S)$, whose growth rate, $g_{\chi_{t}^{X}}=\dot{\chi}_{t}^{X} / \chi_{t}^{X}$, is exogenous. We will return to the assumptions we make on these growth rates below in Section 4 , when we run the quantitative exercise. One can think of these productivity parameters as reflecting jointly the levels of physical capital, of human capital, and of technological knowledge reached in each of the three sectors. ${ }^{9}$ The production functions are

$$
A_{t}=\chi_{t}^{A} L_{t}^{A}, M_{t}=\chi_{t}^{M} L_{t}^{M} \text { and } S_{t}=\chi_{t}^{S} L_{t}^{S}
$$

where $A_{t}, M_{t}$ and $S_{t}$ denote the total output of agriculture, of manufacturing, and of services, respectively. We use a very simple formalization (Cobb-Douglas with labor as the sole input) in order to emphasize the key role played by non-homothetic productivity gains across sectors. Furthermore, as it will be developed below in 3.3, in spite of their simplicity, these assumptions on technologies when joined to the assumption on the saturations in the demands of agricultural and manufactured goods enables us to obtain straightforwardly results that replicate well the stylized facts presented in Section 2. One could consider production functions depending more explicitly

\footnotetext{
${ }^{9}$ One could also consider that they are influenced by other factors such as institutions, human factors.
} 
on various inputs such as land, physical capital, human capital, knowledge. ${ }^{10}$ However, this extra complexity is not necessary to replicate the stylized facts.

The markets for the agricultural good, manufactured good and services are perfectly competitive. In each sector, firms maximize their profits $\pi_{t}^{X}=p_{t}^{X} \chi_{t}^{X} L_{t}^{X}-L_{t}^{X}(X=A, M, S)$. Since one consider constant returns in production functions with one input, perfect competition implies that the three supply functions are perfectly elastic: $p_{t}^{X}=1 / \chi_{t}^{X}(X=A, M, S)$.

\subsection{Equilibrium}

We can now compute the general equilibrium (prices and quantities) for each of the three phases. Given the supply functions, as seen in Lemma 4 below, the prices are given by the same expression in each of the three phases.

Lemma 4. In the three phases, the price of the agricultural good, of the manufactured good, and of the services are

$$
p_{t}^{A}=1 / \chi_{t}^{A} ; p_{t}^{M}=1 / \chi_{t}^{M} \text { and } p_{t}^{S}=1 / \chi_{t}^{S} \text {, respectively }
$$

Then, the quantities $a_{t}, m_{t}$ and $s_{t}$ of per capita consumptions, and the quantities $L_{t}^{A}, L_{t}^{M}$ and $L_{t}^{S}$ of labor for each phase are provided in the three propositions below.

Phase I - No saturations: $a_{t}<\bar{a}$ and $m_{t}<\bar{m}\left(t<t^{\bar{a}}\right)$

In the following proposition, we exhibit the results for Phase I.

Proposition 1. Before any saturation occurs (i.e. $\forall t$ such that $t<t^{\bar{a}}$ ), the equilibrium labor partition is

$$
L_{t}^{A}=\alpha L, L_{t}^{I}=\mu L \text { and } L_{t}^{S}=\sigma L ;
$$

and the equilibrium per capita consumptions of the agricultural good, the manufactured good and services are

$$
a_{t}=\alpha \chi_{t}^{A}, m_{t}=\mu \chi_{t}^{M} \text { and } s_{t}=\sigma \chi_{t}^{S} \text {, respectively }
$$

Proof. From (5) and (9), one gets the per capita consumptions levels: $a_{t}=\alpha \chi_{t}^{A}, m_{t}=\mu \chi_{t}^{M}$ and $s_{t}=\sigma \chi_{t}^{S}$. Then, the labor partition is derived from market clearing conditions. One has $A_{t}=L a_{t} \Leftrightarrow \chi_{t}^{A} L_{t}^{A}=L \alpha \chi_{t}^{A} \Leftrightarrow L_{t}^{A}=\alpha L ; M_{t}=L m_{t} \Leftrightarrow \chi_{t}^{M} L_{t}^{M}=L \mu \chi_{t}^{M} \Leftrightarrow L_{t}^{M}=\mu L$; and $S_{t}=L s_{t} \Leftrightarrow \chi_{t}^{S} L_{t}^{S}=L \sigma \chi_{t}^{S} \Leftrightarrow L_{t}^{S}=\sigma L$.

During Phase I, as shown in (10), the share of labor devoted to each sector is constant and depends on the preferences of the representative household. Besides, as shown in (11), the consumption of the agricultural good, of the manufactured good, and of services increase according to $a_{t}=\alpha \chi_{t}^{A}, m_{t}=\mu \chi_{t}^{M}$ and $s_{t}=\sigma \chi_{t}^{S}$, respectively. The demand for the agricultural good reaches its saturation level $\bar{a}$ at the end of Phase I, that is at date $t^{\bar{a}}: \alpha \chi_{t^{\bar{a}}}^{A}=\bar{a}$. At this date one enters Phase II, in which consumption henceforth remains constant: $a_{t}=a_{t^{\bar{a}}}=\bar{a}, \forall t \geq t^{\bar{a}}$.

Phase II - Saturation in the demand for the agricultural good 8 no saturation in the demand for the manufactured good: $a_{t}=\bar{a}$ and $m_{t}<\bar{m}\left(t^{\bar{a}} \leq t<t^{\bar{m}}\right)$

In the following proposition, we exhibit the results for Phase II.

Proposition 2. Once the saturation level of the demand for the agricultural good has been reached, and before the saturation level of the demand for the manufactured good has been reached, that is $\forall t \in\left[t^{\bar{a}} ; t^{\bar{m}}\right.$, the equilibrium labor partition is

$$
L_{t}^{A}=\frac{\bar{a}}{\chi_{t}^{A}} L, L_{t}^{M}=\frac{\mu}{\mu+\sigma}\left(1-\frac{\bar{a}}{\chi_{t}^{A}}\right) L \text { and } L^{S}=\frac{\sigma}{\mu+\sigma}\left(1-\frac{\bar{a}}{\chi_{t}^{A}}\right) L ;
$$

\footnotetext{
${ }^{10}$ In particular, it appears more realistic to introduce the use of land in the agriculture, and the use of physical capital in manufacturing. We consider extensions of our model (available upon request), in which the production of the agricultural (resp. manufactured) good is formalized by a Cobb-Douglas with two inputs: labor and land (resp. physical capital). These generalizations do not change significantly the key features of our model, even though they enable it to replicate even more accurately the stylized facts of interest. Furthermore, the choice of Cobb-Douglas could also be debated; however, in addition to its tractability, Herrendorf et al. (2015) show that "Cobb-Douglas sectoral production functions that differ only in technical progress capture the main technological forces behind the postwar US structural transformation".
} 
and the equilibrium per capita consumptions of the agricultural good, the manufactured good and services are

$$
a_{t}=\bar{a}, m_{t}=\frac{\mu}{\mu+\sigma}\left(1-\frac{\bar{a}}{\chi_{t}^{A}}\right) \chi_{t}^{M} \text { and } s_{t}=\frac{\sigma}{\mu+\sigma}\left(1-\frac{\bar{a}}{\chi_{t}^{A}}\right) \chi_{t}^{S}, \text { respectively } .
$$

Proof. From (9), one has $p_{t}^{A}=1 / \chi_{t}^{A}, p_{t}^{M}=1 / \chi_{t}^{M}$ and $p_{t}^{S}=1 / \chi_{t}^{S}$. Plugging in (6), one has $m_{t}=$ $\frac{\mu\left(1-p_{t}^{A} \bar{a}\right)}{(\mu+\sigma) p_{t}^{M}}=\frac{\mu\left(1-\bar{a} / \chi_{t}^{A}\right)}{(\mu+\sigma) / \chi_{t}^{M}}=\frac{\mu}{\mu+\sigma}\left(1-\frac{\bar{a}}{\chi_{t}^{A}}\right) \chi_{t}^{M}$ and $s_{t}=\frac{\sigma\left(1-p_{t}^{A} \bar{a}\right)}{(\mu+\sigma) p_{t}^{S}}=\frac{\sigma\left(1-\bar{a} / \chi_{t}^{A}\right)}{(\mu+\sigma) / \chi_{t}^{S}}=\frac{\sigma}{\mu+\sigma}\left(1-\frac{\bar{a}}{\chi_{t}^{A}}\right) \chi_{t}^{S}$. Market clearing conditions give the labor partition: $A_{t}=L a_{t} \Leftrightarrow \chi_{t}^{A} L_{t}^{A}=L \bar{a} \Leftrightarrow L_{t}^{A}=\frac{\bar{a}}{\chi_{t}^{A}} L$; $M_{t}=L m_{t} \Leftrightarrow \chi_{t}^{M} L_{t}^{M}=L \frac{\mu}{\mu+\sigma}\left(1-\frac{\bar{a}}{\chi_{t}^{A}}\right) \chi_{t}^{M} \Leftrightarrow L_{t}^{M}=\frac{\mu}{\mu+\sigma}\left(1-\frac{\bar{a}}{\chi_{t}^{A}}\right) L ;$ and $S_{t}=L s_{t} \Leftrightarrow \chi_{t}^{S} L_{t}^{S}=$ $L \frac{\sigma}{\mu+\sigma}\left(1-\frac{\bar{a}}{\chi_{t}^{A}}\right) \chi_{t}^{S} \Leftrightarrow L_{t}^{S}=\frac{\sigma}{\mu+\sigma}\left(1-\frac{\bar{a}}{\chi_{t}^{A}}\right) L$.

While during Phase I, the labor partition across the three sectors was constant, Phase II is characterized by structural changes (i.e. a reallocation of the labor force across the broad sectors agriculture, manufacturing and services): as seen in (12), the quantity of labor devoted to agriculture decreases; this freed labor force reallocates into manufacturing and services. Furthermore, As shown in (13), during this phase, the consumption of the agricultural good (having reached its saturation level at date $t^{\bar{a}}$ ) remains constant and equal to $\bar{a}$. Furthermore, the consumptions of the manufactured good and of services now increase along with $m_{t}=\frac{\mu}{\mu+\sigma}\left(1-\bar{a} / \chi_{t}^{A}\right) \chi_{t}^{M}$ and $s_{t}=\frac{\sigma}{\mu+\sigma}\left(1-\bar{a} / \chi_{t}^{A}\right) \chi_{t}^{S}$, respectively. At date $t^{\bar{m}}$ (end of Phase II), it is now the turn of the demand for the manufactured good to reach its saturation level $\bar{m}: \frac{\mu}{\mu+\sigma}\left(1-\bar{a} / \chi_{t^{m}}^{A}\right) \chi_{t^{\bar{m}}}^{M}=\bar{m}$. Henceforth, the consumption of manufactured goods remains $m_{t}=m_{t^{\bar{a}}}=\bar{m}, \forall t \geq t^{\bar{m}}$.

Phase III - Saturation in the demands for both agricultural and the manufactured good: $a_{t}=\bar{a}$ and $m_{t}=\bar{m}\left(t^{\bar{m}} \leq t\right)$

The following proposition exhibits the results for Phase III.

Proposition 3. Once the saturation levels of the demands for the agricultural good and for the manufactured good have been reached, that is for $\forall t \geq t^{\bar{m}}$, the equilibrium labor partition is

$$
L_{t}^{A}=\frac{\bar{a}}{\chi_{t}^{A}} L, L_{t}^{M}=\frac{\bar{m}}{\chi_{t}^{M}} L \text { and } L^{S}=\left(1-\frac{\bar{a}}{\chi_{t}^{A}}-\frac{\bar{m}}{\chi_{t}^{M}}\right) L
$$

and the equilibrium per capita consumptions of the agricultural good, the manufactured good, and services are

$$
a_{t}=\bar{a}, m_{t}=\bar{m} \text {, and } s_{t}=\chi_{t}^{S}\left(1-\frac{\bar{a}}{\chi_{t}^{A}}-\frac{\bar{m}}{\chi_{t}^{M}}\right) \text {, respectively } .
$$

Proof. For any $t \geq t^{\bar{m}}$, one has $a_{t}=\bar{a}$ and $m_{t}=\bar{m}$. From (7), one has $s_{t}=\frac{1-p_{t}^{A} \bar{a}-p_{t}^{M} \bar{m}}{p_{t}^{S}}$; using the prices $\left(p_{t}^{A}=1 / \chi_{t}^{A}, p_{t}^{M}=1 / \chi_{t}^{M}\right.$ and $\left.p_{t}^{S}=1 / \chi_{t}^{S}\right)$ derived in (9), one gets $s_{t}=$ $\frac{1-\bar{a} / \chi_{t}^{A}-\bar{m} / \chi_{t}^{M}}{1 / \chi_{t}^{S}}=\left(1-\frac{\bar{a}}{\chi_{t}^{A}}-\frac{\bar{m}}{\chi_{t}^{M}}\right) \chi_{t}^{S}$. Market clearing conditions give the labor partition: $A_{t}=$ $L a_{t} \Leftrightarrow \chi_{t}^{A} L_{t}^{A}=L \bar{a} \Leftrightarrow L_{t}^{A}=\frac{\bar{a}}{\chi_{t}^{A}} L ; M_{t}=L m_{t} \Leftrightarrow \chi_{t}^{M} L_{t}^{M}=L \bar{m} \Leftrightarrow L_{t}^{M}=\frac{\bar{m}}{\chi_{t}^{M}} L ;$ and $S_{t}=L s_{t} \Leftrightarrow \chi_{t}^{S} L_{t}^{S}=L\left(1-\frac{\bar{a}}{\chi_{t}^{A}}-\frac{\bar{m}}{\chi_{t}^{M}}\right) \chi_{t}^{S} \Leftrightarrow L_{t}^{S}=\left(1-\frac{\bar{a}}{\chi_{t}^{A}}-\frac{\bar{m}}{\chi_{t}^{M}}\right) L$.

As seen in (14), Phase III (like Phase II) is also characterized by structural changes. The quantity of labor devoted to agriculture continues to decrease. After reaching a peak at date $t^{\bar{m}}$, the quantity of labor devoted to manufacturing starts to decline. The labor force freed from these two sectors reallocates into services. Besides, as shown in (15), during Phase III, the consumption of the agricultural good and of services, which have both reached their saturation levels (at dates $t^{\bar{a}}$ and $t^{\bar{m}}$, respectively), remain constant and equal to $\bar{a}$ and $\bar{m}$, respectively. Finally, from date $t^{\bar{m}}$ (end of Phase II / beginning of Phase III) the only consumption increasing is the one of services: $s_{t}=\chi_{t}^{S}\left(1-\frac{\bar{a}}{\chi_{t}^{A}}-\frac{\bar{m}}{\chi_{t}^{M}}\right)$.

Fig. A, B and C. Around here 
Our model - which considers saturations of the demands for rival goods and non-homothetic productivity gains - leads to clear theoretical results (independently of the calibrations that will be made below in Section 4). Figures A, B and C summarize and illustrate the general equilibrium results provided in Lemma 4 and Propositions 1, 2 and 3: economic development is characterized by three distinct phases, the patterns of which match major stylized facts.

First, as shown by (10), (12) and (14), the model exhibits structural changes in the labor partition across sectors (see Figure A). Assuming $\alpha>\mu>\sigma$, Phase I is characterized by more labor in the agriculture than in manufacturing and in services; assuming furthermore that $g_{\chi_{t}^{M}}>g_{\chi_{t}^{S}}$, Phase II sees a reallocation of labor from the agriculture into the two others sectors (more into manufacturing than into services at first); and during Phase III, the shares of labor in manufacturing and in services asymptotically vanish, all the labor force being reallocated into services in the long run. Second, as shown by (11), (13) and (15), assuming that $g_{\chi_{t}^{M}}>g_{\chi_{t}^{A}}>g_{\chi_{t}^{S}}$, the model replicates the observed changes in the structure of consumptions (see Figure B). Indeed, under this assumption, Phase I exhibits the development of the agriculture first, followed successively by the ones of manufacturing and of services, while Phase II sees the share of income devoted manufactured goods increases faster that the one devoted to services. ${ }^{11}$ Third, as seen in (9), the model reproduced the evolution of prices which all decrease differently according to the productivity gains (see Figure $\mathrm{C}$, in which prices are expressed in terms of the wage and their initial values are normalized to unity).

In Section 4 below, we illustrate the capability of the model to reproduces accurately well established empirical observations. As seen in 4.2, this qualitative exercise enables us to show that our model not only reproduces well overall patterns of economic development but - given a reasonable calibration (see 4.1) - also generates results quantitatively close to the observed facts (see Section 2 above).

\section{Quantitative Exercise}

In order to run some quantitative analysis, we need to calibrate the parameters of the model. In that respect, we rely on economic history to determine rough but sensible values for each of these parameters. Two sets of parameters are required. First, we need calibrations for the parameters of the representative household's preferences: the saturation thresholds of the demands for agricultural products and for manufactured products $(\bar{a}$ and $\bar{m})$, and the parameters of the Cobb-Douglas utility function (i.e. the weights $\alpha, \mu$ and $\sigma$ put on each of the three goods in the preferences). Second, on the production side, we need to calibrate the productivity gains in each of the three sectors, and in particular their long run growth rates $\left(g_{\chi_{t}^{A}}\right.$ for agriculture, $g_{\chi_{t}^{M}}$ for manufacturing and $g_{\chi_{t}^{S}}$ for services).

In this section, we provide a basic calibration based on available empirical observations. The use of such rough values constitutes, of course, a methodological simplification of the reality. To demonstrate the robustness of our model, we then provide the results of alternative calibrations below in 4.4.1. Simulations are run for the period 1450-2350.

\subsection{Calibration}

\subsubsection{Preferences of the representative household}

\section{Saturation levels of the demands for rival goods ( $\bar{a}$ and $\bar{m}$ )}

Regarding the saturation thresholds in agricultural and manufactured products, we look for sensible coefficients of multiplication between the initial level of the demand and its saturation threshold.

For the saturation level $\bar{a}$ of the demand for the agricultural good, we deduce a level of satiety from long-term data on food consumption. A first indication is offered by the comparisons of calories absorbed then and now. The subsistence level is about 1,200 Kcal per day for one person. Today, the worldwide highest consumption is observed in Austria with 3,800 Kcal per day (FAO data). This level represents a multiplicative by about 3 . This factor of multiplication is probably a minimum and we can estimate that the current calories consumption is made of higher quality products (e.g. the consumption of apple has probably been multiplied by a higher figure but

\footnotetext{
${ }^{11}$ Figure $\mathrm{B}$ describes the evolution of the equilibrium per capita quantities of each of the three goods. Hence, it does not exactly represent the stylized fact regarding the evolution of GDP per capita depicted in Figure 2 above. In that respect, one needs to aggregate those three quantities to obtain a measure of GDP per capita. In 4.2 , we compute a standard real GDP per capita using, as common basis of aggregation, the initial prices (see Figure 4).
} 
there is no doubt that a saturation also occurred). Studying a luxury good, the consumption of champagne has been multiplied by 13 between 1900 and today; 157.74 million of bottles have been drunk in France in 2016 meaning 2.35 bottle per French per year versus 7.43 million or 0.18 per French in 1900 (data from the Comité Interprofessionnel du vin de Champagne). As a matter of calibration, we roughly retain a multiplicative factor of 5 .

As for the saturation level $\bar{m}$ of the demand for the manufactured good, its estimation is more delicate. Using historical studies on various industrial activities, we inferred a rough estimation. Metallurgical industry in Europe provides a first indication. In 1400, the total consumption was between 25 and 30 thousand tons (Sprandel, 1969) for a population of 45 million, that is between 0.55 and 0.66 kilograms per capita. Nowadays, the total consumption amounts to 150 million of tons (Eurofer report 2016) for a population of 508 million, that is a consumption of 295 kilograms per capita, which has remained relatively stable for a few decades. ${ }^{12}$ Therefore, the coefficient of multiplicative between the initial level of the demand and its saturation threshold lies between 443 and 531. A second indication is provided by the change in the annual level of CO2 emissions. In the 1800, the industrialization in the US was very weak as reflected by a level of 0.03 tons per capita. Nowadays, this figure has reached 16 tons, that is a multiplicative factor of 533 (see Carbon Dioxide Information Analysis Center through Gapminder website). ${ }^{13}$ Another hint can be obtained from the consumption of shoes. Every American purchased 7.5 pairs of shoes in 2013. In $200 \mathrm{BC}$, Cato the Elder recommended to provide each worker with one pair of robust shoes every other year (De Agri Cultura, LIX). Hence a multiplicative factor of $15 .{ }^{14}$ As a matter of calibration, we roughly retain a multiplicative factor of 400 .

These estimations are necessarily a bit coarse; nevertheless, our theoretical framework appears to be quite robust since it still replicates the stylized fact under alternative calibrations (see below in 4.4.1-a.).

\section{Parameters of the Cobb-Douglas utility function $(\alpha, \mu$ and $\sigma)$}

We know that, in the absence of saturation, the parameters $\alpha, \mu$ and $\sigma$ give the shares of income spent in the consumptions of the agricultural good $(\alpha)$, the manufactured good $(\mu)$ and services $(\sigma)$. As shown in Proposition 1, at the general equilibrium of our model, they also are the share of labor devoted to each of the three sectors during Phase I (i.e. from the beginning of the process of development until the take off which occurs when the demand for the agricultural good reaches saturation). There is no debate about the fact that at least $70 \%$ of the population worked in agriculture for centuries (see empirical evidences presented in Section 2; especially Wallis et al., 2017). Accordingly, we use this fact in order to calibrate the parameter $\alpha$. Besides, we assume that the remaining $30 \%$ are equally shared between manufacturing and services. ${ }^{15}$ Obviously, one may wonder how reasonable it is to consider those parameters to be constant over time. Regarding this matter, let us recall that even if the Cobb-Douglas with saturations utility function remains unchanged over time, the saturations lead to modifications in the demand functions from phase to the other (see Lemmas 1, 2 and 3).

\subsubsection{Sectorial productivity gains}

We have assumed that the evolution of the marginal productivity of labor in each sector $\left(\chi_{t}^{A}, \chi_{t}^{M}\right.$ and $\left.\chi_{t}^{S}\right)$ is exogenous, resulting from a combination of accumulation of physical capital, of human capital and of knowledge (see the presentation of the technologies (8) in Section 3.2). The initial values of the parameters of these "stocks of capital" are all normalized to one at the beginning of the period. As we consider that each sector produces a homogenous good, the retained value for the productivity gains in each sector should correspond to the average gain observed in this sector for the long run. ${ }^{16}$ To use the more reasonable values, we rely on the existing literature in economic history. As we detailed below, historical evidence support the idea that the productivity gains rose over time. A behavior that our model neglects (but that could be added in our quantitative exercise) because this is not necessary to capture the main stylized facts. Accordingly, we fav or

\footnotetext{
${ }^{12}$ According to European Coal and Steel Community (1957), per capita consumption was already around $300 \mathrm{~kg}$ in the $1950 \mathrm{~s}$.

${ }^{13}$ Of course, this figure is rough because industry is obviously not only the producer of CO2.

${ }^{14}$ Even if rather low (compared to the ones obtained using consumption of steel or CO2 emissions), this factor is still much higher than the ones obtained for the saturation of the demand of agricultural products.

${ }^{15}$ In 4.4.1- b., we consider alternative calibration ( $\alpha=70 \%, \sigma=20 \%$ and $\mu=10 \%$ ); our key results remain.

${ }^{16}$ In 4.4.1-c., we show that our model is quite robust to the values of these parameters.
} 
simplicity by determining very rough rates of productivity gains over the whole period (1450-2000) by aggregating estimations made for shorter historical periods: we compute the geometric average of very different rates which are typical of the long period of slow growth (before 1800) and of the more recent period of rapid growth (after 1800).

There is a rich literature assessing the productivity gains in the agriculture in the long run. In Campbell \& Overton (1996), the productivity gains in the English agriculture over the period 1300-1800 are estimated at $0.16 \%$ per year. Still in England, Clark (2002) estimates them at $0.15 \%$ for the period 1500-1869. Hoffman (1996) finds growth rates during the Old Regime that range from $-0.16 \%$ to $0.31 \%$, depending on French regions and on types of production. More recently, the production of wheat has experienced productivity gains of $0.8 \%$ per year between 1750 and 1929 in norther France (Grantham, 1991). Besides, according to available data from the OECD, the annual productivity gains in the agriculture observed in member countries between 1990 and 2009 have reached $1.86 \%$ per year. ${ }^{17}$ To summarize, the average productivity gains in the agricultural sector have remained below $0.2 \%$ for centuries until they significantly increased over the past two centuries. Then, a rough estimation can consist in the geometric average combining $0.2 \%$ (1450$1800), 0.8 \%$ (1800-1950) and 1.8\% (1950-2000); it thus appears reasonable to consider an average annual productivity gain $g_{\chi_{t}^{A}}=0.4 \%$ in the long run.

Productivity gains in manufacturing have also been extensively studied but mainly since the Industrial Revolution. Studies have led to diverse estimations depending on authors, on industries, and on time periods; not to mention the various methodologies used to assess these gains. Several authors argue that the productivity gains in manufacturing during the Industrial Revolution in England were probably relatively limited (e.g. $0.34 \%$ in Crafts, 2004). Broadberry et al. (2015) estimate at $0.93 \%$ the yearly productivity gains in English manufacturing between 1759 and 1851 . Others have stressed high rates in some key industries: $2.3 \%$ in textiles or $1.8 \%$ in iron and steel (Clark, 2014). Fuchs (1964) provides a figure regarding all manufactured goods which is limited to 2.44\% over 1929-1961 in the US. Field (2006) puts forward annual averages ranging from $0.57 \%(1973-1989)$ to $5.12 \%(1919-1929)$ in the US. Data from the OECD show that member countries have experienced annual productivity gains in manufacturing of $2.96 \%$ in average over 1990-2016. Given the diversity on the available estimations, we suggest to consider an average annual productivity gain for the manufacturing sector $g_{\chi_{t}^{M}}=1 \%$. This rate can be obtained as the geometric average of $0.2 \%(1450-1800)$ and $3 \%$ (1800-2000); or, alternatively, of $0.3 \%$ (1450-1800), $2 \%(1800-1950)$ and $4 \%(1950-2000)$.

The services sector gathers various activities. It can be argued that productivity gains in many tertiary activities have remained almost nil in the long run; for instance, the services provided by a monk, a teacher, or a prostitute. Some others services have experience very low gains (e.g. barbers, professional cleaners, ...). Besides, some others enjoyed occasional important gains; let think about the transport (train, plane, ...), or accounting (computer). When it comes to global estimates, Fuchs (1964) observes an average productivity gain in the services amounting to $0.70 \%$ in the US for the period 1929-1961. Regarding the more recent period, which benefits from the ICT revolution, the average productivity gains in the "business sector services" reached $1.78 \%$ in OECD members over the 1990-2009 period. ${ }^{18}$ Then, as a rough approximation, we retain for the calibration an average annual productivity gain $g_{\chi_{+}^{S}}=0.2 \%$; which corresponds to the geometric average of $0.01 \%$ (1450-1900), $0.7 \%$ (1900-1950) and 1.7\% (1950-2000). It is important to note that the value of this productivity parameter does not affect the capability of our model to reproduce the stylized facts previously mentioned. In fact, the value of this parameter modifies only the growth rate during the last period, the value of which remains an open question.

\subsection{Replication of Stylized Facts}

Using the calibration presented in 4.1, our model roughly reproduces the three stylized facts depicted above in Section 2. As mentioned above in 4.1.2, the initial levels, $\chi_{0}^{A}, \chi_{0}^{M}$ and $\chi_{0}^{S}$, of the "stocks of capital" are all normalized to unity; accordingly (see (9) in Lemma 4), the initial price of each of the three goods is $1 .^{19}$ To give an illustrative timing, we assume that the simulated

\footnotetext{
${ }^{17}$ Data retrieved online OECD.stat (ISIC Rev.3).

${ }^{18}$ Data retrieved online OECD.stat (ISIC Rev.3). It could be argued that the recent period has in fact experienced much lower productivity gains in the services; for instance, controlling for mismeasurement of productivity growth, Young (2014) observes an average gain of productivity in the services of $0.2 \%$ in 18 OECD countries (1970-2005)

${ }^{19}$ Note that using different values - for instance 70, 15 and 15, that is assuming that the initial "stocks of capital" result from a past accumulation, which would have followed the same pattern as the one leading to the initial labor partition across the three sectors (which depends on the initial preferences of the representative household) - does
} 
economy starts in 1450, a date that corresponds to the end of the Hundred Years' war, beginning of a long period of stability favorable to development.

First, as illustrated by Figure 4, we reproduce the structural changes regarding the share of workers in each sector. Whereas the labor partition remains the same during Phase I, the saturation in the agricultural good allows workers to move to manufacturing and services in Phases 2 and 3. The share of workers in manufacturing reaches a maximum to about one third while agriculture and services employed about an identical third. This repartition was observed in western Europe in the middle of the 20th century. Since this maximum, the share of manufacturing joins the agricultural labor force in a gradual decline while the share in service increases. Ultimately, our model predicts that, thanks to productivity gains, workers in the two first sectors will fall to about nothing, services becoming the dominant occupation.

\section{Fig. 4. Around here}

The second stylized fact reproduced is the pattern of the economic growth. Because, it requires to add goods and services that vary over time (and for those which remain, their prices also vary), assessing economic growth is a complicated task. ${ }^{20}$ Aware of this difficulty, we use a standard methodology to compute a measure of economic growth: the real GDP using date $t=0$ (year 1450 on the figure) as the base year. ${ }^{21}$ Figure 5 represents the GDP per capita predicted by our model. In order to provide a visual figure consistent with empirical observations, as basis we use the GDP per capita of 1,000 US Dollar of 1990 estimated by Bolt \& van Zanden (2014) for England in 1450. Our model produces a first phase of slow but positive growth before a strong increase during Phase II, vanishing in a new era of very limited growth in the third phase. The magnitude of the rise of GDP per cap is higher than what is observed today in Western Europe (about 25,000 dollars instead of 65,000 in our figure); few developed countries are close to this level and maybe the shocks resulting from wars, especially those of the 20th century could explain this difference.

\section{Fig. 5. Around here}

The third stylized fact reproduced is the evolution of prices of the three goods over time. In Figure 6, we depict the prediction of the model over the full period, but the patterns are similar over shorter horizons, for instance the 20th century as in Figure 3 (real prices of bread, electric bulb and male haircut). All three prices clearly decrease. We find a decline in the price of the manufactured good which is much more stronger than the one of the agricultural good. Besides, the price of services follows a much slower decline; here we replicate the famous Baumol's "cost disease". The underlying source of these patterns is the non-homothetic productivity gains.

\section{Fig. 6. Around here}

\subsection{Additional Outcomes}

In addition to these three stylized facts we reproduce here two interesting outputs of our model. The first one is the real GDP growth rate observed over time. As seen in Figure 7, this rate, which is below $0.60 \%$ per year at the beginning of the period, gradually increases during Phase I, reaching a level of about $1.20 \%$ during Phase II. Our model expects very limited growth in Phase III, period during which growth is mainly driven by the low productivity gains in services. The abrupt changes exhibited in Figure 6 is due to the strong simplification along which we assume of a brutal change between phases. ${ }^{22}$ A smoother pattern could be obtained using a more general model but would induce an useless complexity. Anyway, the GDP growth rate our model produce are highly consistent, even in magnitude, with what has been observed for developed countries.

\section{Fig. 7. Around here}

\footnotetext{
not affect the outcomes of the model.

${ }^{20}$ Jean Fourastié was highly reluctant to compute an aggregated measure of production or consumption over time.

${ }^{21}$ Using a real GDP expressed in prices of $t=0$ is a way to express the increase in the standard of living enjoyed by a household of this initial epoch). Alternatively, using a chained GDP would produce different patterns but since the stylized facts assessed in this paper are expressed in real GDP, we obviously retain the same measure.

${ }^{22}$ In fact, the first brutal change results from the fact that at date $t^{\bar{a}}$, the marginal worker moves from agriculture to manufacturing; the latter being characterized by much higher productivity gains than the former. Similarly, the second jump results from the fact that at date $t^{\bar{m}}$, the marginal worker moves from manufacturing to services; the latter being characterized by much lower productivity gains than the former.
} 
The second interesting output of our model is the global productivity gains of labor observed in the economy over time, which rely on two features: i. the productivity gains in each sector, and ii. the structural changes in the labor partition. To assess the evolution of the overall productivity of labor, we use an index, denoted by $\chi_{t}$, computed as the average of the productivity levels in the three sectors weighted by the share of labor in each sector: $\chi_{t}=L_{t}^{A} \chi_{t}^{A}+L_{t}^{M} \chi_{t}^{M}+L_{t}^{S} \chi_{t}^{S}$, where $L_{t}^{X}$ and $\chi_{t}^{X}$ are the quantity of labor and the productivity of labor in each sector $X(X=A, M, S)$. As seen in Figure 8, during Phase I, the overall productivity of labor is stable. Then, in Phase II, it rises as the share of labor in manufacturing increases; the maximum productivity corresponds to the point at which the share of the labor force in manufacturing is the highest. Then, as the share of labor in the service increases, this overall productivity of labor decreases. Note that one could somehow be tempted to relate this outcome to the one of the Total Factor Productivity (TFP); indeed, Figure 8 looks like the famous "one big wave" in the TFP stressed by Gordon (2000). However, the notion of TFP is complicated to assess empirically (OECD, 2001).

\section{Fig. 8. Around here}

\subsection{Robustness Exercises}

\subsubsection{Alternative calibrations}

In this section, we investigate whether our results are dependent on the parameters we have used in the calibration. To demonstrate the robustness of our model to the parameters used, we successively modify several of them, maintaining others at the levels used above. To save space, we only reproduce the outcome which we assume to be the most significant: the structural changes in the share of workers.

a) The most delicate estimation is the saturation level of the demand for manufactured products; the one of the demand for agricultural products seems less problematic. Instead of considering a multiplicative factor of 400, we use successively 4,000 (resp. 100). As seen in Figures 9 and 10, such a change delays (resp. move forward) the date at which saturation occurs and increases (resp. reduces) the share of labor in manufacturing to be reached to get to saturation.

Fig. 9 and 10. Around here

b) A second set of alternative calibration is the initial partition of labor (i.e. the parameters of the Cobb-Douglas utility function $\alpha, \mu$ and $\sigma$ ). There is no doubt that about $70 \%$ of the population worked in the agriculture (thus, we retain $\alpha=70 \%$ ); however, assuming that the $30 \%$ remaining were equally split between manufacturing and services can be criticized. Especially, it appears that an important share of the labor force worked as servant in pre-development Europe (Szoltysek, 2009). Accordingly, we increase the share in services $\sigma$ to $20 \%$ (and thus reduce the one in manufacturing, $\mu$, to $10 \%)$; and then, for comparison, we test the opposite $(\sigma=10 \%$ and $\mu=20 \%$ ). As seen in Figures 11 and 12, in both cases, the general pattern remains similar even though the magnitude of the increase in the share of labor in manufacturing varies quite significantly.

\section{Fig. 11 and 12. Around here}

c) A third set of alternative calibration relates to the productivity gains rates we have used. Instead of the numbers we have retained as explained in 4.1.2, we double (resp. halve) the three rates. As seen in Figures 13 and 14, the main patterns are similar except that saturations occur earlier (resp. later, in fact so much later that the saturation in manufactured products is not observed on our timing), and with little differences in the labor repartition.

\section{Fig. 13 and 14. Around here}

\subsubsection{Modeling the Roman economy}

A final exercise is to modify the parameters to fit the main characteristics of the Roman economy. ${ }^{23}$ Since human being remains the same over time, we can assume that saturation levels were rather

\footnotetext{
${ }^{23}$ We focus on the case of the Roman economy but other historical episode such as the Pharaonic Egypt or the Imperial China were about similar.
} 
identical in Antiquity. The saturation in agricultural products has been probably reached during the Roman times. Evidence of this saturation in is offered by the share of labor devoted to other activities than agriculture (important urban population, soldiers). A second evidence is the use of harvester in Gaul as documented by writing and engraving. ${ }^{24}$ This machine collecting ears thanks to a kind of comb pushed by beefs saved human labor but wasted important part of the crop. Such an arbitrage testifies that the value of grain in term of wage was already low. But, despite this high productivity level in agriculture, the Romans never experienced something comparable to the industrial revolution never reaching the saturation in manufactured products. On the contrary, services were well developed as indicated by the numbers of baths and public arenas; 41 arenas have been identified in Gaul with at least ten receiving more than 20,000 spectators. The labor freed from agricultural work was transferred to manufacturing but also to services at a large scale.

Such an economy can be reproduced within our model by modifying only the productivity gains observed in the manufacturing sector. Let us assume that the productivity gains in manufacturing were identical to the ones in agriculture $(0.40 \%)$. This assumption can be legitimated by the fact that even if, by its deep nature, manufacturing is more sensitive to technical progress, the conditions of the Roman time did not allow this higher propensity to express it. The lack of printing could have made much more difficult the spread of one innovation in manufacturing whereas innovation in agriculture could diffuse thanks to contagion because this activity is geographically continuous. More generally, it can be argued that since then, the past millennium has seen several General Purpose Technologies (GPTs) affecting more strongly manufacturing (e.g. waterwheel, steam, electricity). ${ }^{25}$ Another rationale could be that the stock of knowledge and capital was much lower in manufacturing at this time: since Neolithic and the beginning of agriculture, human civilization focused on food production rather than on manufacturing.

Assuming productivity in manufacturing identical to the one in agriculture, both the share of service and manufacturing increases after saturation in food production but despite centuries, the saturation is far to be reached in manufactured products. Regarding the GDP (based at 1), this economy enjoyed a growing increase but never experienced the abrupt rise observed in western Europe after 1800.

\section{Fig. 15 and 16. Around here}

In our model, the fall of the Roman Empire following the Great Migration means a destruction of the "stocks of capital" $\chi_{t}^{A}, \chi_{t}^{M}$ and $\chi_{t}^{S}$ (i.e. destruction of physical and human capital, loss of knowledge). These destructions led to a fall in the productivity and to the well-documented fall in consumption per capita. The Carolingian domination started a new phase of stable institutions allowing another episode of development imposing to starting from close to scratch the process. This second episode culminated at the beginning of the second millennium. At this time, the saturation was reached again in agricultural products, allowing a large part of the labor force to be dedicated to other activities (Crusades or building cathedrals). The Great Plague of 1348 and the Hundred Years' war reduced a second time the "stocks of capital". The stability reached again from 1450 allowed the third episode of development we have described in this paper. This episode was long enough and with productivity gains high enough to permit to reach for the first time in human history the saturation in manufactured goods.

\section{Conclusion}

This paper introduces a new theoretical framework to assess economic development, which formalizes the analysis proposed by Jean Fourastié (1949). Our model assumes three sectors characterized by different productivity gains (high in manufacturing, medium in agriculture and low in services) and saturations of the demands for agricultural and manufactured goods. These two set of assumptions are supported by important historical evidence. Adopting a simple general equilibrium model (in particular, we consider Cobb-Douglas utility function and one factor Cobb-Douglas production functions), the derived quantities (per capita consumptions and labor partition) and prices match well three major observed stylized facts. First, the theoretical results depict structural changes in the labor partition across the three sector. More precisely, the equilibrium partition of lab or

\footnotetext{
${ }^{24}$ The large presence of low-cost labor through slavery in Italian peninsula seems to explain why harvester was not use there.

${ }^{25}$ For more details on GPTs, see Bresnahan \& Trajtenberg (1995).
} 
experiences three phases: 1. constant labor partition until saturation in the demand for agricultural good occurs, 2. reallocation of the labor force from agriculture into manufacturing and services until saturation in the demand for manufactured good occurs, and 3. constant increase in the share of services. Second, the model exhibits three phases of different growth regimes (a first period of low secular growth turning to a period of fast growth before reaching a new stable phase, potentially of secular stagnation). Third, the model captures well the patterns of the evolution of relative prices in each of the three sectors. Furthermore, not only our theoretical results replicate these stylized facts, but calibrated with reasonable values, the model also predicts patterns very close, even in magnitude and timing, to the ones observed in economic history (these results are robust to the use of alternative calibrations).

Following the principle to favor simplicity, we have presented a unmannerly version of our model because more complexity turns out to be unnecessary to capture the hereinbefore mentioned stylized facts. In fact, keeping this first version simple enables us to testify its robust ability to capture major stylized facts. For the model to be more realistic, one could consider several obvious extensions. The utility function could be refined to consider less abrupt occurrences of saturations; thus providing predictions of smoother changes from one phase to the other. Technical progress could be endogenized, thus enabling us to consider more accurate evolution of the productivity gains over time (instead of assuming rough averages ones). Besides, the capability of our model to help in the understanding of other economic issues can also be investigated. Including physical capital in the model would enables us to determine an interest rate; this would help explain its historical evolution, especially the recent strong decrease. Including land would provide some insight on the evolution of its market value over time. Considering interactions between two countries experiencing different phases within the process of development could enables us to provide some new insights on international trade. Finally, introducing a distinction between high and low skilled labor - especially in the services - could help understand the recent polarization in the job market. 


\section{References}

[1] Acemoglu, D., Guerrieri, V. (2008) Capital Deepening and Non-Balanced Economic Growth. Journal of Political Economy 116, 467-498.

[2] Aghion, P., Howitt, P. (1992) A model of growth through creative destruction. Econometrica $60.2,323-351$.

[3] Alcouffe, A., Le Bris, D. (2016) Our Secular Stagnation as Expected by Jean Fourastié, 1949. Working paper.

[4] Allen, R. C. (1999) Tracking the Agricultural Revolution in England. Economic History Review $52.2,209-235$.

[5] Allen, R.C. (2000) Economic structure and agricultural productivity in Europe, 1300-1800, European Review of Economic History 3, 1-25.

[6] Baumol, W. (1967) Macroeconomics of Unbalanced Growth: The Anatomy of Urban Crisis. American Economic Review 57.3, 415-426.

[7] Baumol, W. J. (2004) The cost disease of the personal services. In Rowley, C., Schneider, F. (eds.) The Encyclopedia of the Public Choice. New-York: Springer, pp. 132-136.

[8] Bolt, J., van Zanden, J. L. (2014) The Maddison Project: collaborative research on historical national accounts. Economic History Review 67.3, 627-651.

[9] Boppart, T. (2014) Structural Change and the Kaldor Facts in a Growth Model With Relative Price Eects and Non-Gorman Preferences. Econometrica 82, 2167-2196.

[10] Bresnahan, T., Trajtenberg, M. (1995) General Purpose Technologies: "Engines of Growth"? Journal of Econometrics 65.1, 83-108.

[11] Broadberry, S. N., Campbell, B. M. S., Klein, A., Overton, M., van Leeuwen, B. (2015) British Economic Growth, 1270-1870. Cambridge: Cambridge University Press.

[12] Buera, F. J., Kaboski, J. P. (2009) Can Traditional Theories of Structural Change Fit The Data? Journal of the European Economic Association 7, 469-477.

[13] Buera, F. J., Kaboski, J. P. (2012) The Rise of the Service Economy, American Economic Review 102 (6), 2540-2569.

[14] Campbell, B., Overton, M. (1999) Production et productivité dans l'agriculture anglaise, 1086-1871. Histoire \&3 Mesure 11, 255-297.

[15] Chenery, H. B. (1960) Patterns of Industrial Growth. American Economic Review 50.4, 624654 .

[16] Clark, G. (2002) The Agricultural Revolution and the Industrial Revolution: England, 15001912. Working paper.

[17] Clark, G. (2014) The Industrial Revolution. in Aghion, P., Durlauf, S. (eds) Handbook of Economic Growth, Volume 2.

[18] Comin, D.G. Lashkari, D., Mestieri, M. (2015) Structural Change with Long-run Income and Price Effects. NBER Working Paper No. 21595.

[19] Crafts, N. (2004) Productivity Growth in the Industrial Revolution: A New Growth Accounting Perspective, Journal of Economic History 64.2, 521-535.

[20] Echevarria, C. (1997) Changes in Sectoral Composition Associated with Economic Growth. International Economic Review 38.2, 431-52.

[21] Eurofer (2016) Economic and Steel Market Outlook 2016-2017. The European Steel Association.

[22] Feinstein, C. (1999) Structural Changes in the Developed Countries during the Twentieth Century, Oxford Review of Economic Policy 15.4, 35-55. 
[23] Field, A. (2006) Technical Change and U.S. Economic Growth: the Interwar Period and the 1990s in Rhode, P. and Toniolo, G. (eds.) Understanding the 1990s: The Economy in Long Run Perspective. Cambridge: Cambridge University Press.

[24] Fisher, A. G. B. (1939) Production, primary, secondary and tertiary. The Economic Record $15,24-38$.

[25] Foellmi, R., Zweimueller, J. (2008) Structural Change, Engel's Consumption Cycles and Kaldor's Facts of Economic Growth. Journal of Monetary Economics 55, 1317-1328.

[26] Fourastié, J. (1949) Le Grand Espoir du XXème siècle. Paris: PUF.

[27] Fourastié, J. (1979) Les Trente Glorieuses, ou la révolution invisible de 1946 à 1975. Paris: Fayard.

[28] Fuchs, V. R. (1964) Productivity Trends in the Goods and Service Sectors, 1929-61: A Preliminary Survey. NBER.

[29] Galor, O. (2005) From Stagnation to Growth: Unified Growth Theory. In Aghion, P., Durlauf, S. (eds) Handbook of Economic Growth, vol. 1 pp. 171-293. Elsevier Science Publishers.

[30] Gordon, R. J. (2000) Interpreting the "One Big Wave" in U.S. Long-term Productivity Growth. In Van Ark, B., Kuipers, S., Kuper, G. (eds.). Productivity, Technology and Economic Growth. Springer.

[31] Gollin, D., Parente, S., Rogerson, R. (2002) The Role of Agriculture in Development. American Economic Review 92, 160-164.

[32] Grantham, G. (1991) The growth of labour productivity in the production of wheat in the Cinq Grosses Fermes of France, 1750-1929. In Campbell, B. M. S., Overton, M. (eds.) Land, Labour, and Livestock: Historical Studies in European Agricultural Productivity. Manchester: Manchester University Press.

[33] Grossman, G., Helpman, E. (1991) Quality ladders in the theory of growth. Review of Economic Studies 58.1, 43-61.

[34] Guinnane, T., Ogilvie, S. (2008) Institutions and Demographic Responses to Shocks: Württemberg, 1634-1870, Economic Growth Center Discussion Paper No. 962.

[35] Hansen, G. D., Prescott, E. C. (2002) Malthus to Solow. American Economic Review 92.4, 1205-1217.

[36] Herrendorf, B., Herrington, C., Valentinyi, A. (2015) Sectoral Technology and Structural Transformation. American Economic Journal: Macroeconomics 7.4, 104-33.

[37] Herrendorf, B., Rogerson, R., Valentinyi, A. (2013) Two Perspectives on Preferences and Structural Transformation. American Economic Review 103(7), 2752-89.

[38] Herrendorf, B., Rogerson, R., Valentinyi, A. (2014) Growth and Structural Transformation. In Aghion, P., Durlauf, S. (eds) Handbook of Economic Growth, vol. 2, chap. 6, pp. 855-941. Elsevier Science Publishers.

[39] Hoffman, P. (1996) Growth in a Traditional Society: The French Countryside, 1450-1815. Princeton: Princeton University Press.

[40] Humphries, J., Weisdorf, J. (2016) Unreal Wages? A New Empirical Foundation for the Study of Living Standards and Economic Growth in England, 1260-1860. Working paper.

[41] Karabarbounis, L., Neiman, B. (2014). The global decline of the labor share. Quarterly Journal of Economics 129.1, 61-103.

[42] Kongsamut, P., Rebelo, S., Xie, D. (2001) Beyond Balanced Growth. Review of Economic Studies $68.4,869-82$.

[43] Kuznets, S. (1956) Quantitative Aspects of the Economic Growth of Nations. I. Levels and Variability of Rates of Growth, Economic Development and Cultural Change 5, 1-94. 
[44] Laitner, J. (2000) Structural Change and Economic Growth. Review of Economic Studies 67, $545-561$.

[45] Matsuyama, K. (1992) Agricultural Productivity, Comparative Advantage, and Economic Growth. Journal of Economic Theory 58, 317-334.

[46] Matsuyama, K. (2002) The Rise of Mass Consumption Societies. Journal of Political Economy 110, 1053-1069.

[47] Ngai, L. R., Pissarides, C. A. (2007) Structural Change in a Multisector Model of Growth. American Economic Review 97.1, 429-443.

[48] OECD (2001) Measuring Productivity. Paris: OECD.

[49] Piketty, T. (2014) Capital in the Twenty-First Century. Paris: Seuil.

[50] Romer, P. (1990) Endogenous technological change. Journal of Political Economy 98.5, 71-102.

[51] Solow, R. M. (1956) A Contribution to the Theory of Economic Growth. Quarterly Journal of Economics 70.1, 65-94.

[52] Sprandel, R. (1969) La production du fer au Moyen-Age. Annales Economies Sociétés 24.2, 305-321.

[53] Szoltysek, M. (2009) Life cycle service and family systems in the rural countryside: a lesson from historical East-Central Europe. Annales de Démographie Historique 1, 53-94.

[54] Teulings, C., Baldwin, R. (2014) Secular Stagnation: Facts, Causes and Cures. London: CEPR.

[55] Wallis, P., Colson, J., Chilosi, D. (2017) Structural change and economic growth in the British economy before the Industrial Revolution, 1500-1800. Journal of Economic History (forthcoming).

[56] Young, A. (2014) Structural Transformation, the Mismeasurement of Productivity Growth, and the Cost Disease of Services. American Economic Review 104.11, 3635-3667.

[57] Zweimueller, J. (2000) Schumpeterian Entrepreneurs Meet Engel's Law: The Impact of Inequality on Innovation-Driven Growth. Journal of Economic Growth 5, 185-206. 


\section{Employment}
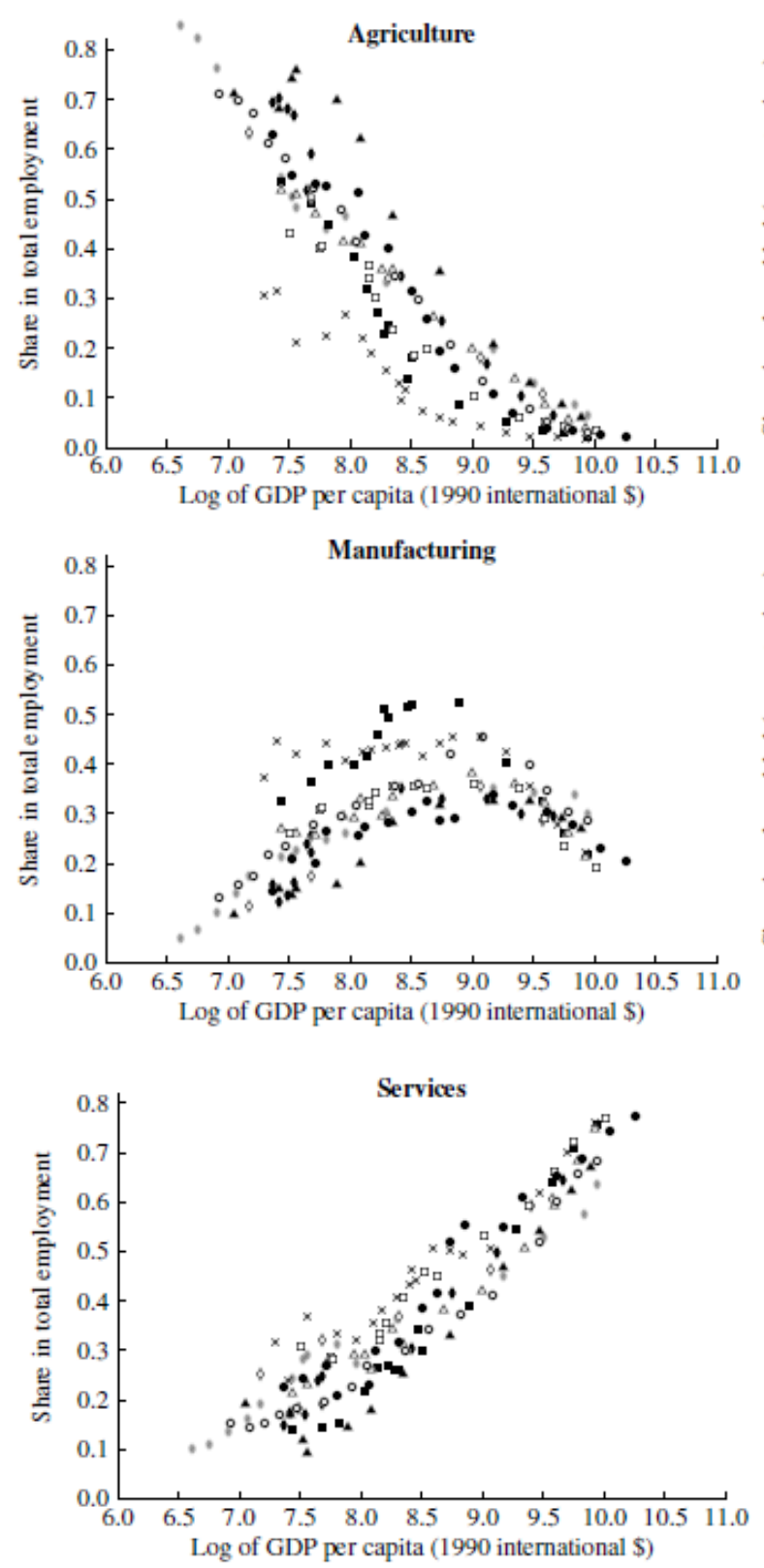

Value added
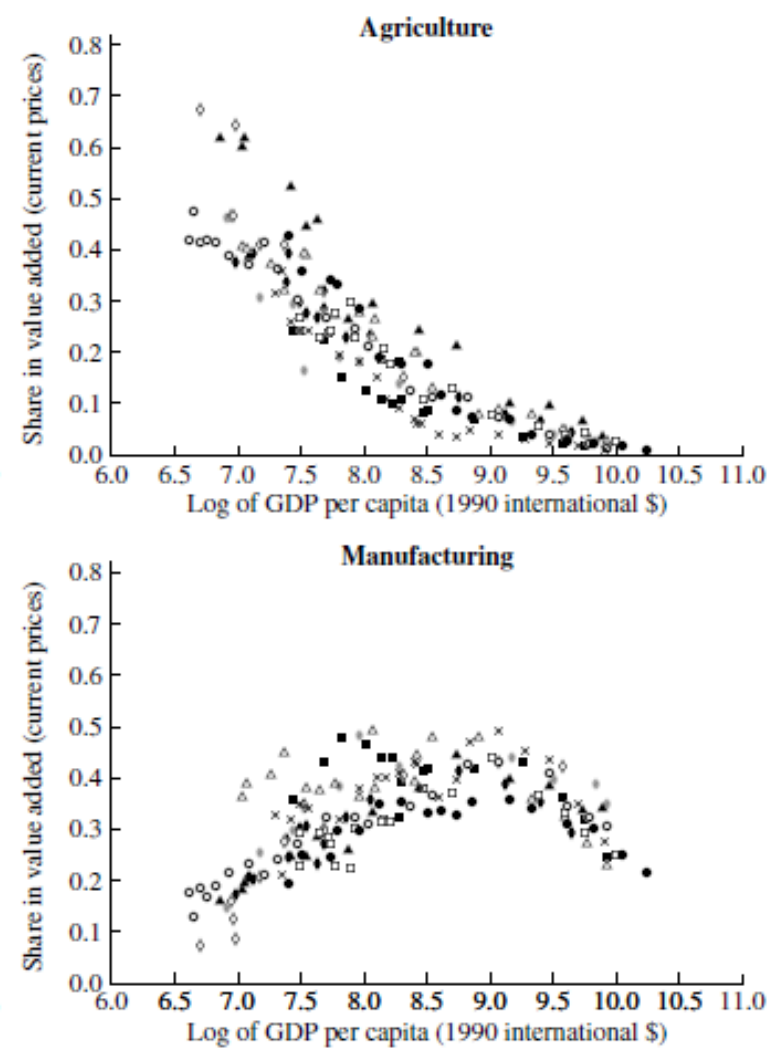

Services

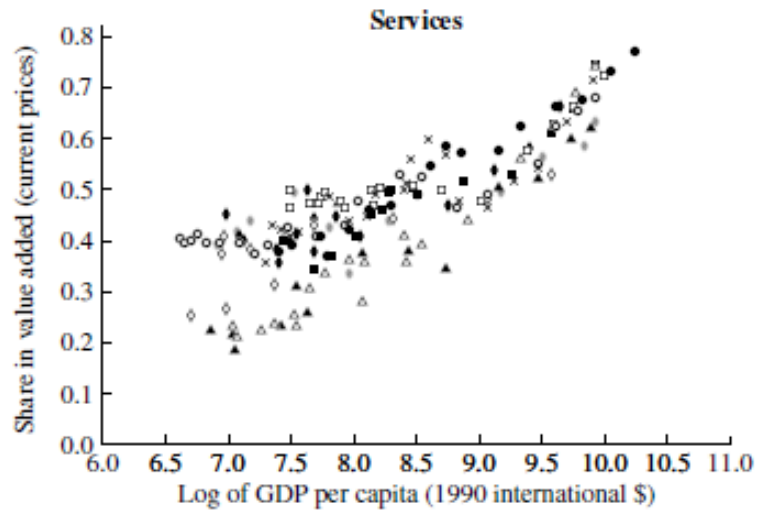

an Belgium $\boldsymbol{\bullet} \bullet$ Spain $\boldsymbol{\Delta} \mathbf{\Delta} \mathbf{\Delta}$ Finland

$\Delta \Delta$ France

***: Japan

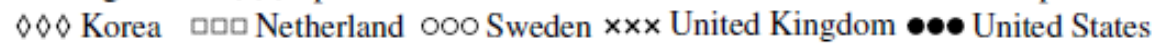

Fig. 1. Sectoral shares of employment and Value added - selected developed countries 1800-2000.

Source: Herrendorf et al. (2014), section 6.2.2.2., Figure 1. 


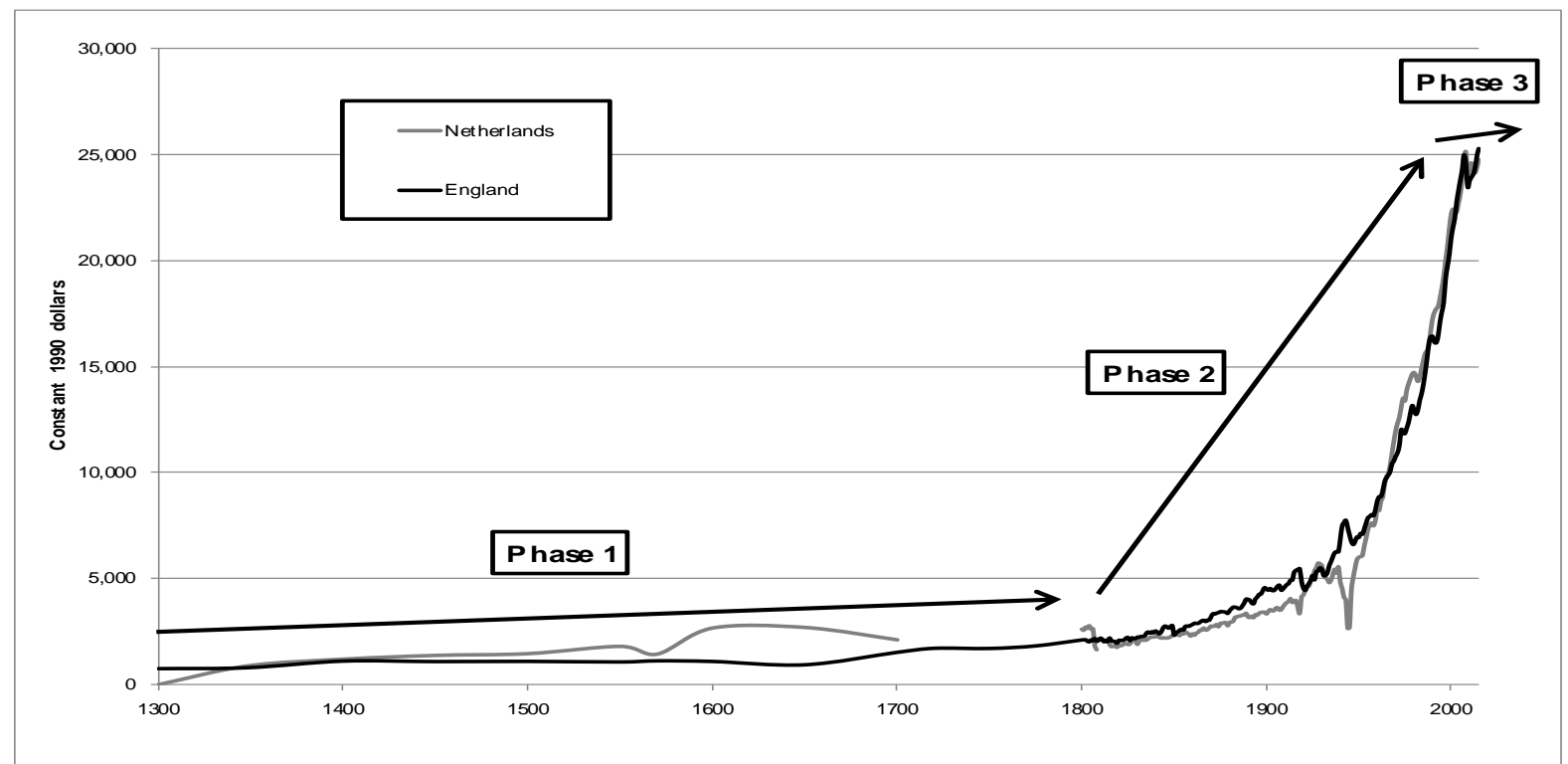

Fig. 2. GDP per capita in England and Netherland, 1300-2015. Source: Bolt \& van Zanden (2014) updated to 2015 according to world bank database.

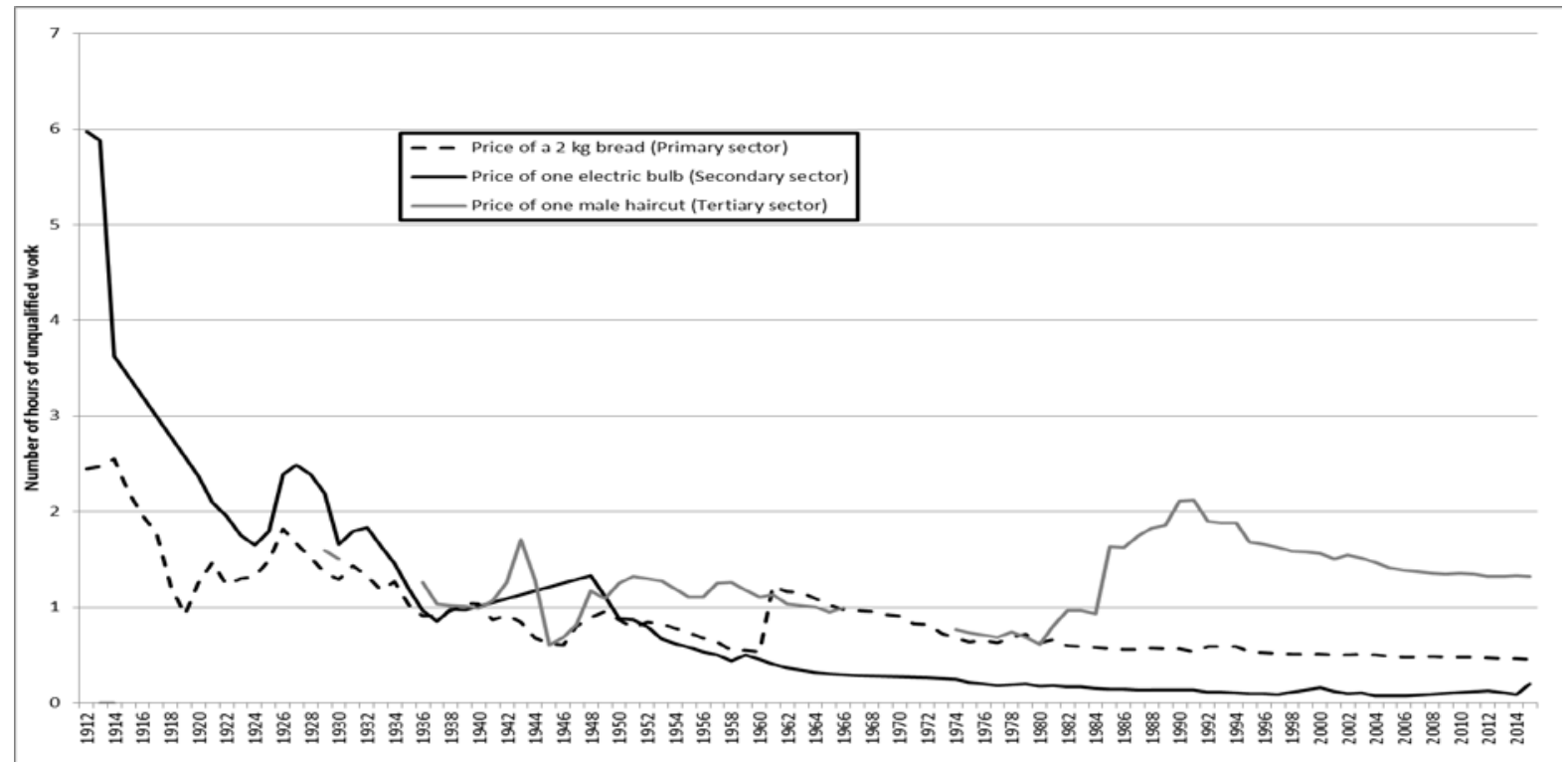

Fig. 3. Real prices of three typical goods.

Source: Comité Fourastié -retrieved from the internet in 0ctober 2016. 


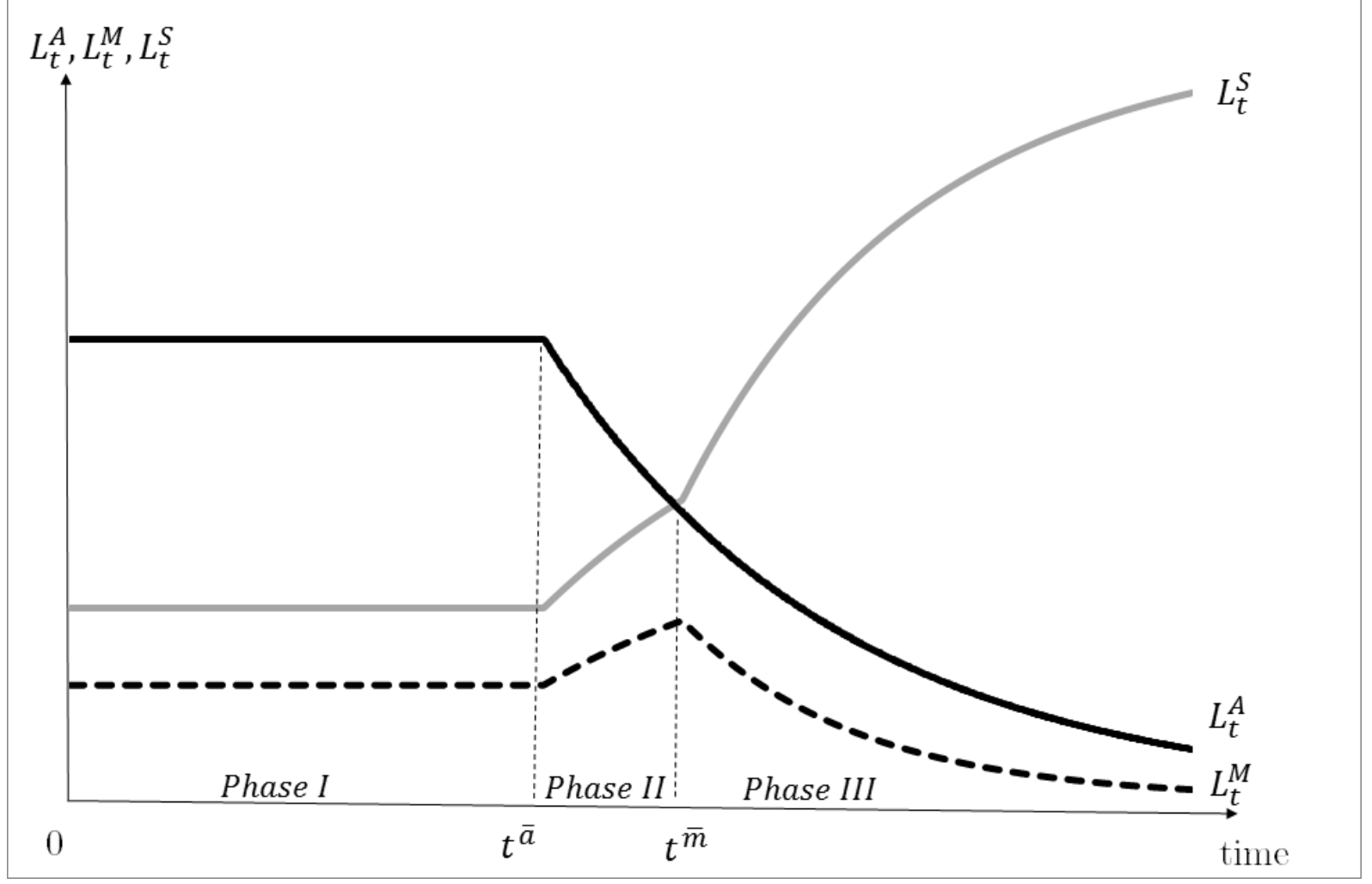

Fig. A. General equilibrium result: structural changes in the labor partition.

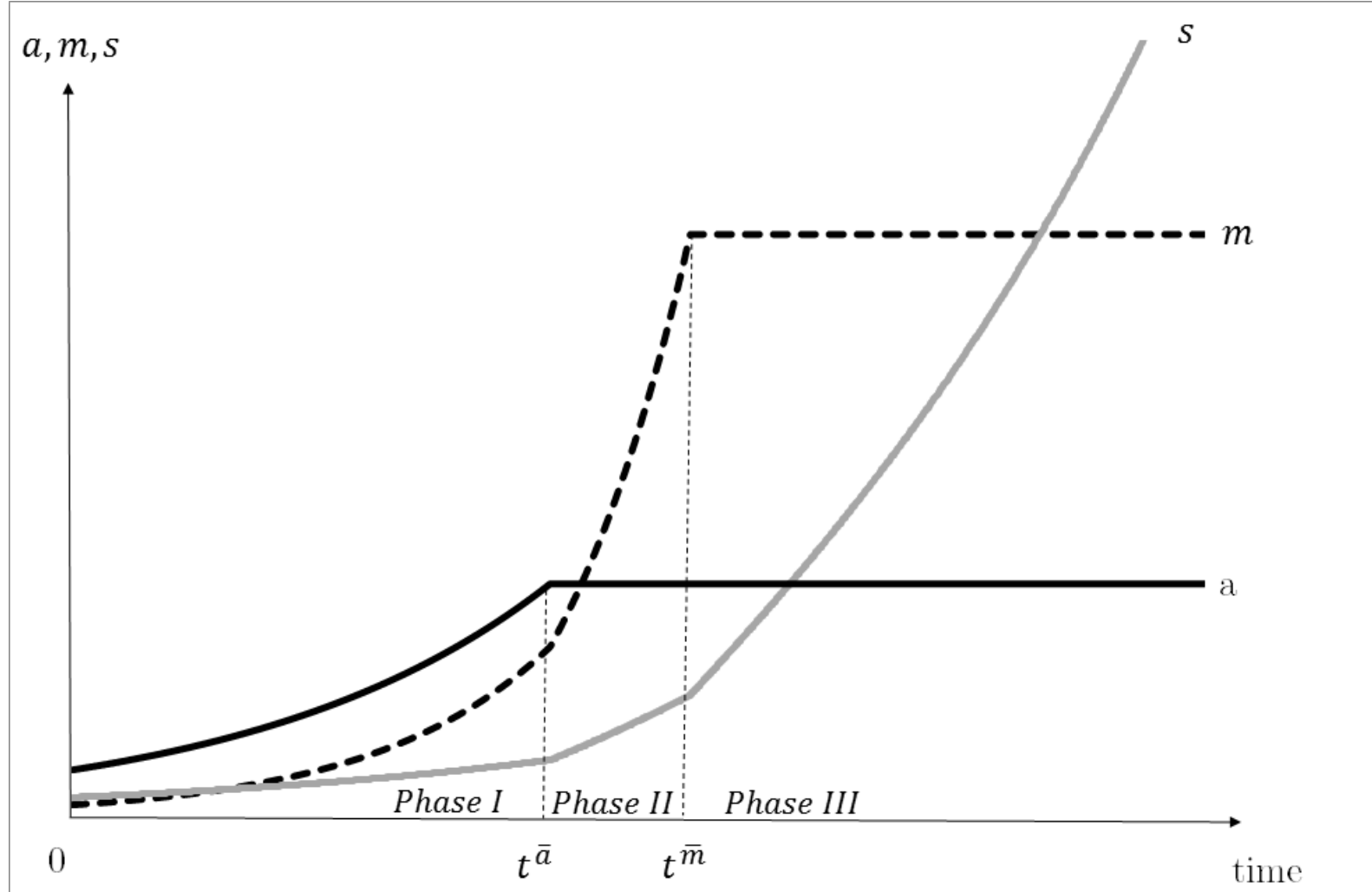

Fig. B. General equilibrium result: evolution of per capita consumptions. 


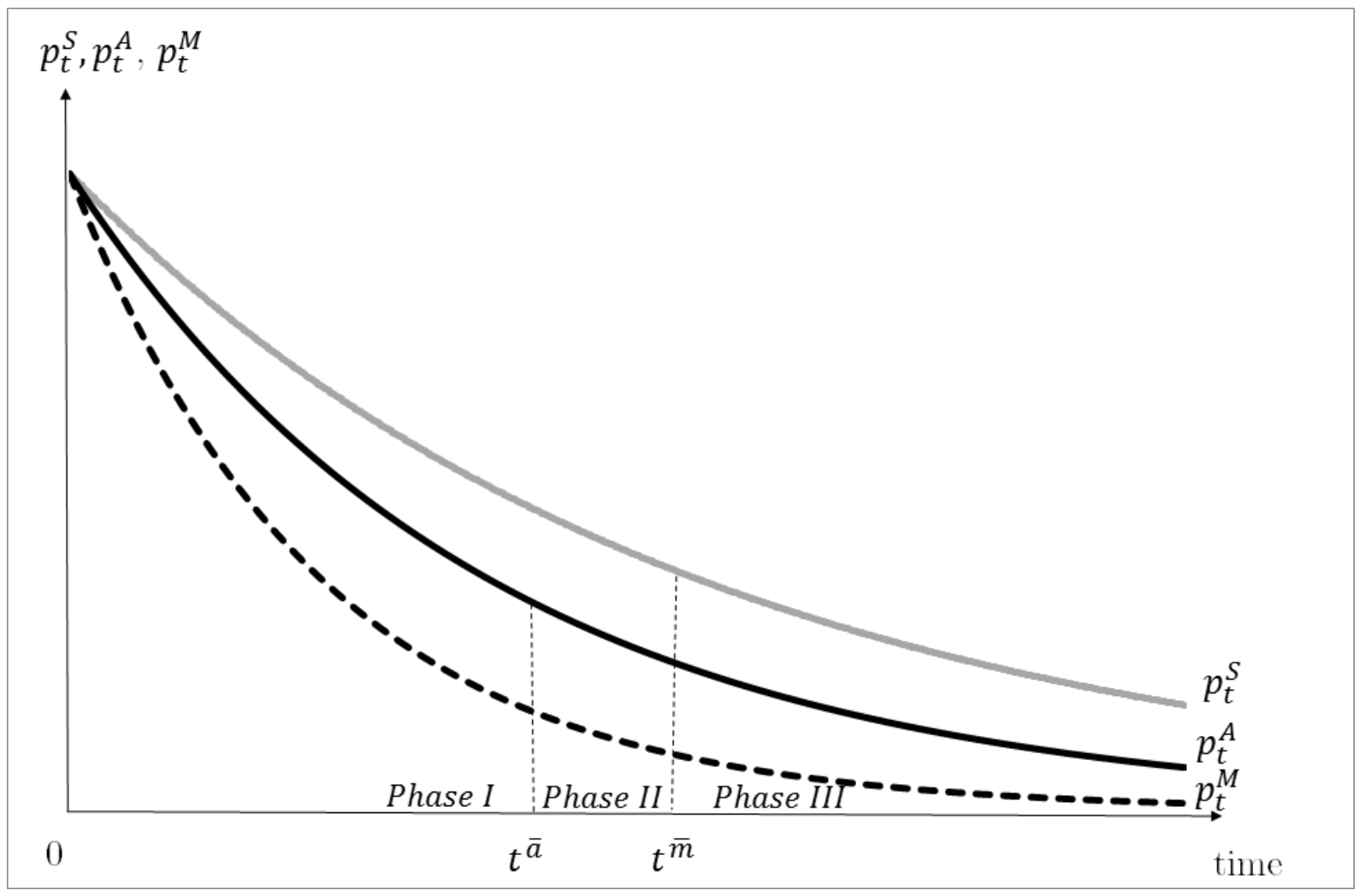

Fig. C. General equilibrium result: evolution of the prices (initial prices and wage normalized to one).

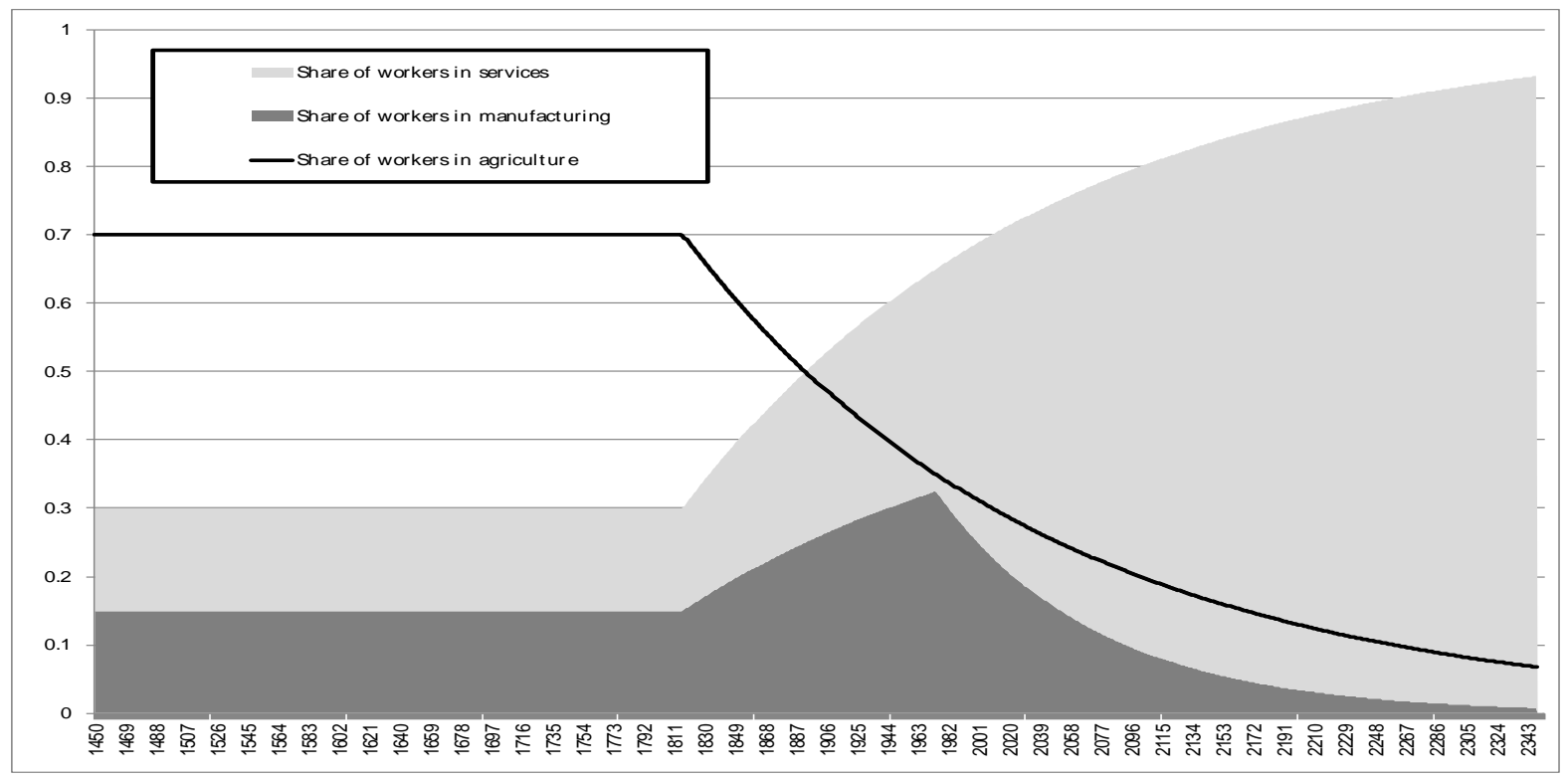

Fig. 4. Share of the labor force in the three sectors (standard calibration). 


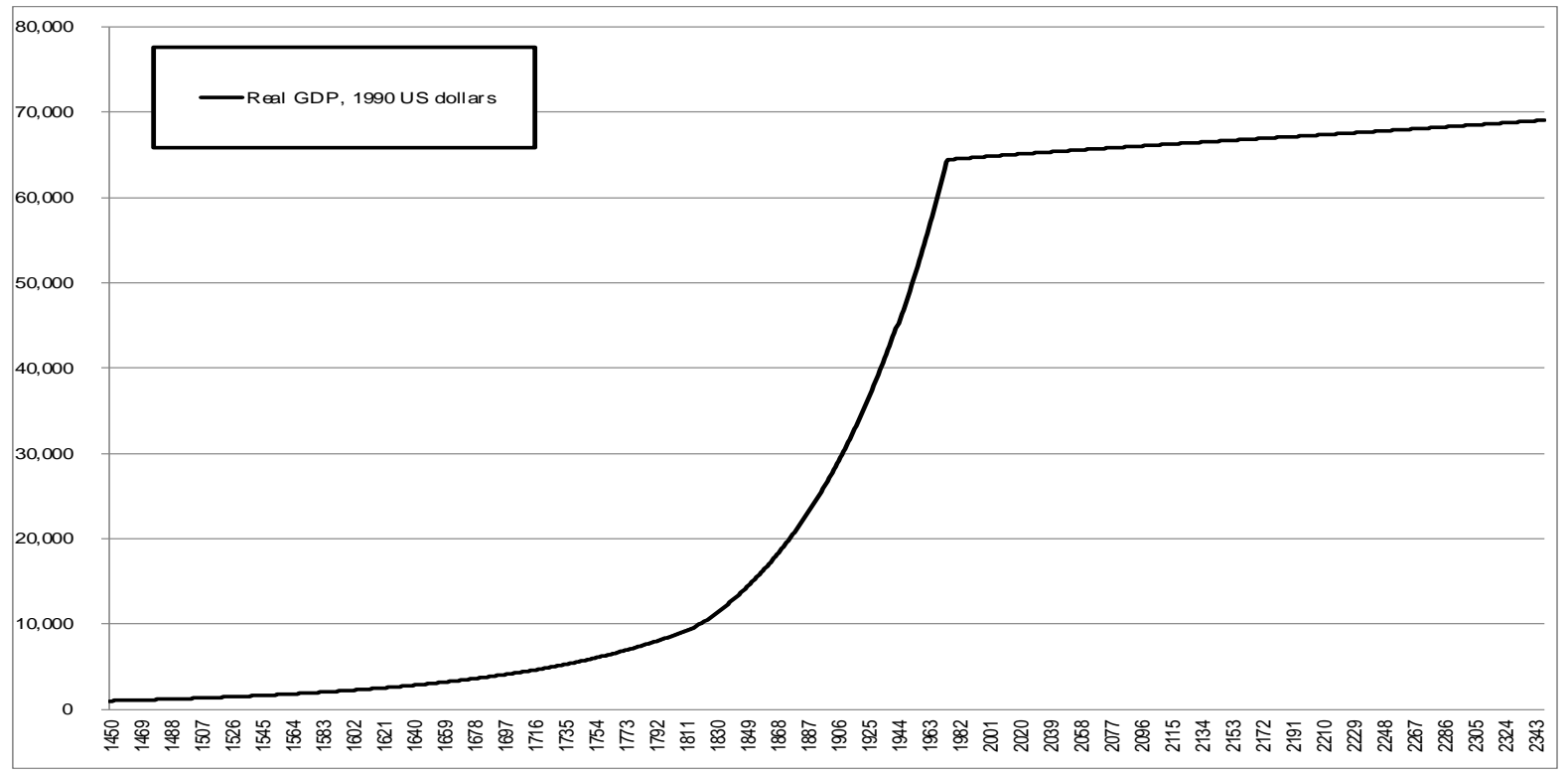

Fig. 5. Real GDP per capita expressed in 1990 US dollars (standard calibration).

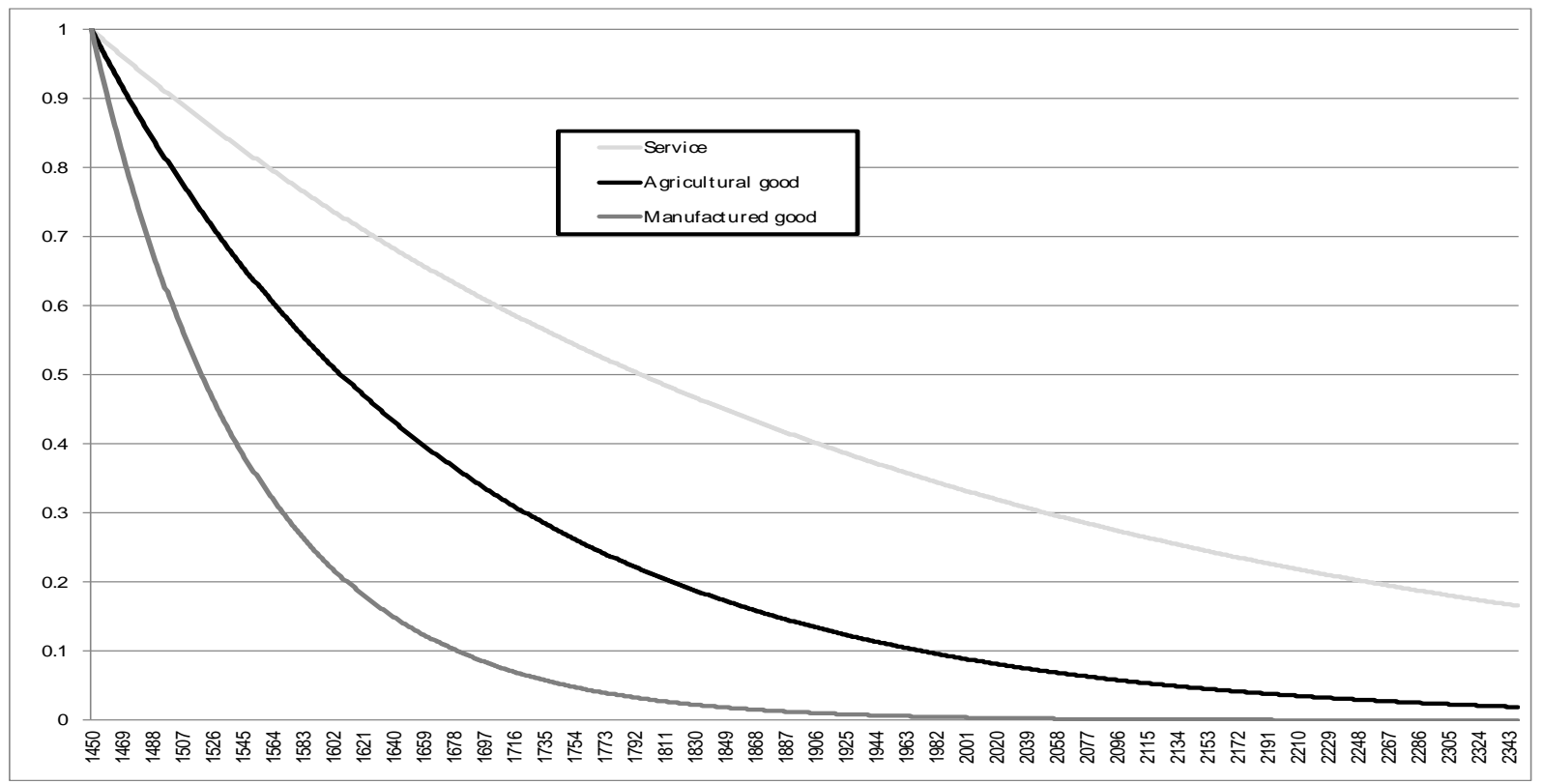

Fig. 6. Prices of the three goods expressed in wage (standard calibration).
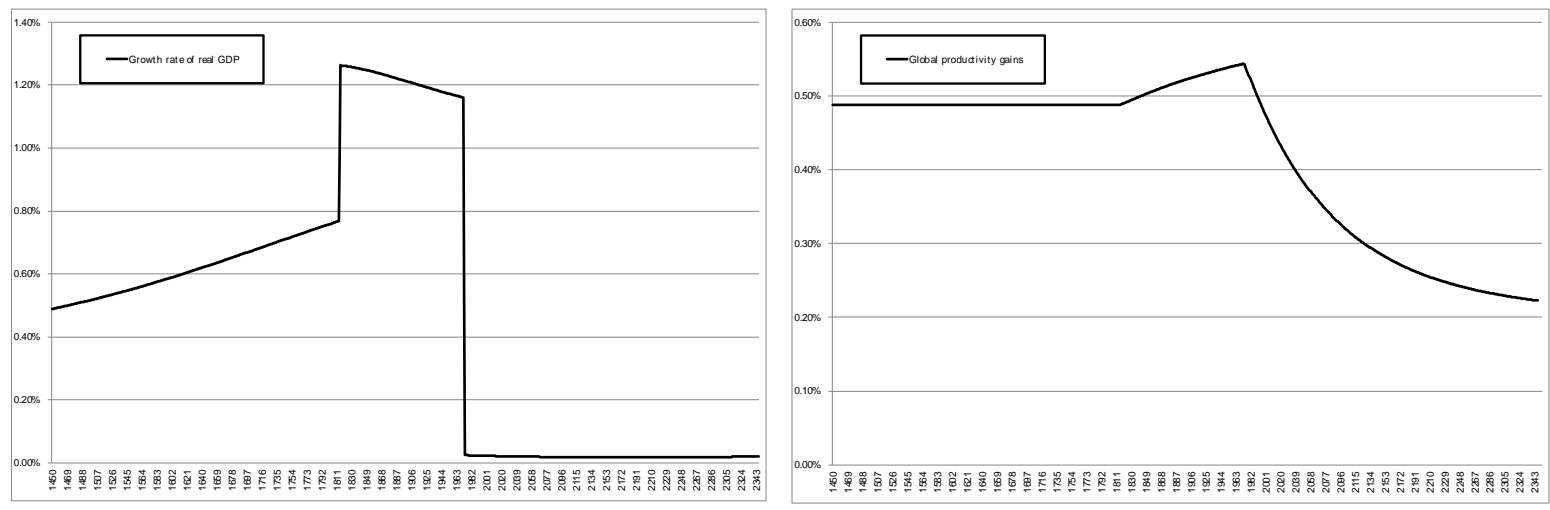

Fig. 7. Real GDP growth rate (st. calib.) Fig. 8 Global productivity gains (st. Calib.) 

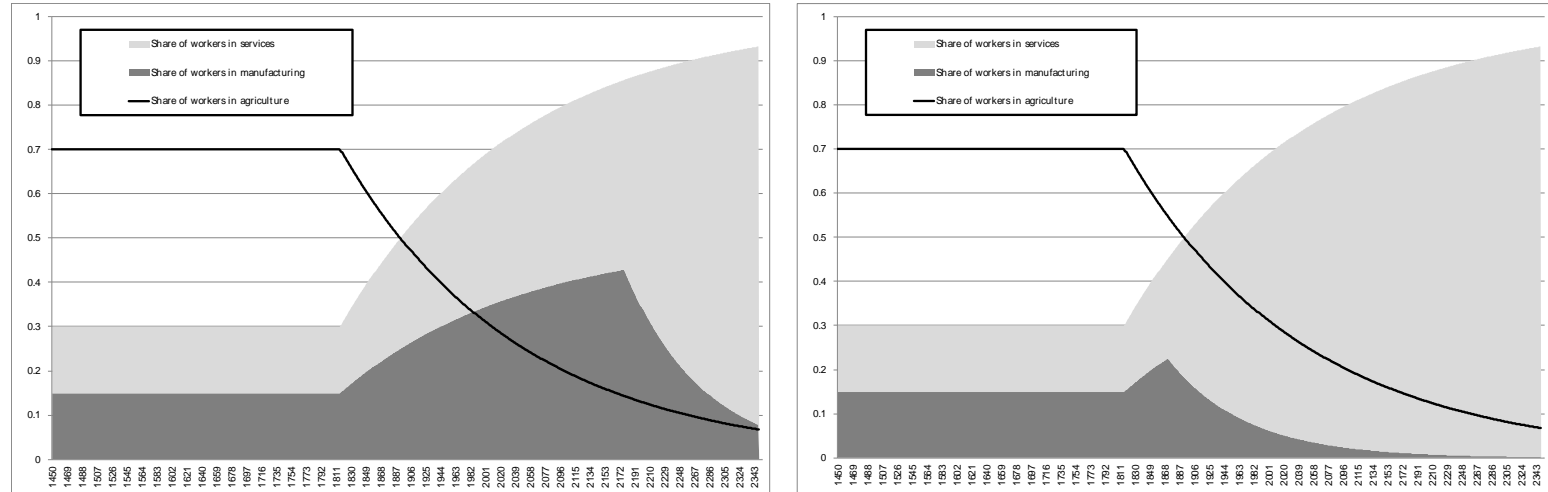

Fig. 9 and 10. Structural changes using saturation in manufactured products at 4,000 (left) and 100 (right) times the initial level.
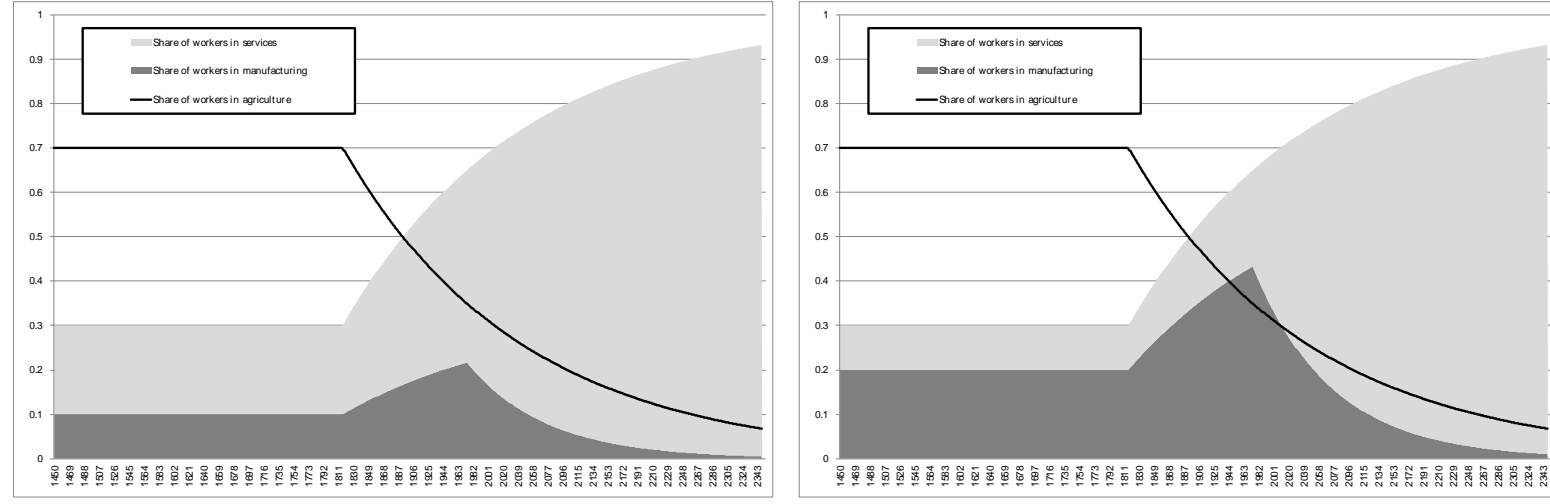

Fig. 11 and 12. Structural changes using $20 \%$ in services and $10 \%$ in manufacturing (left) and the opposite (right) as Cobb-Douglas parameters.
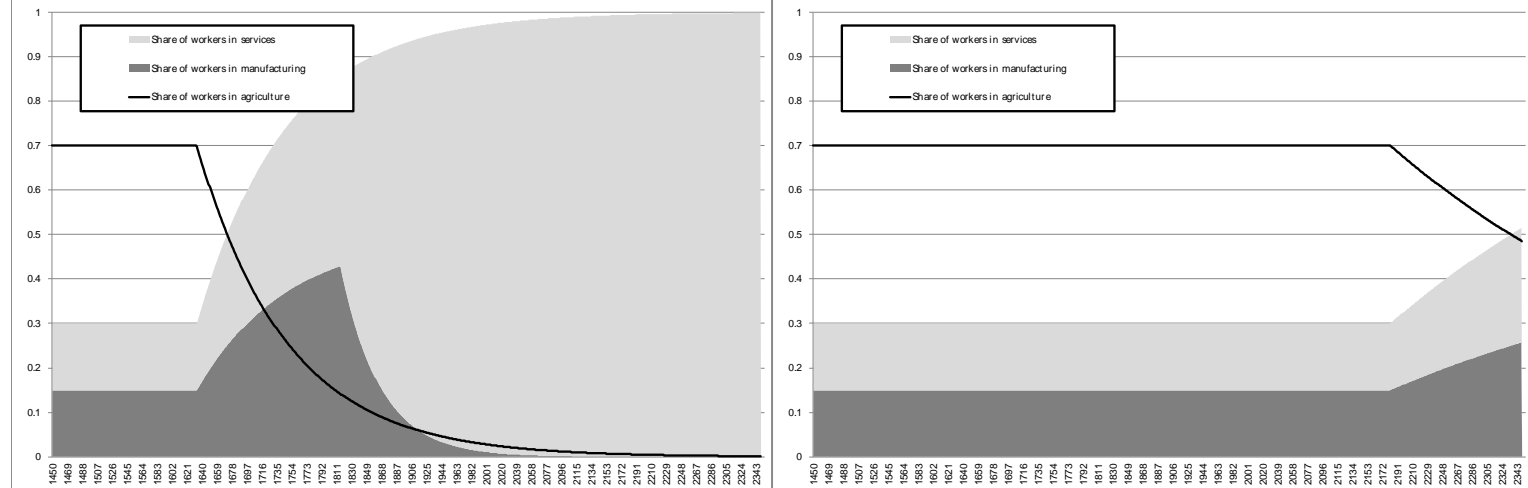

Fig. 13 and 14. Structural changes using productivity gains multiplied by two (left) and divided by two (right).
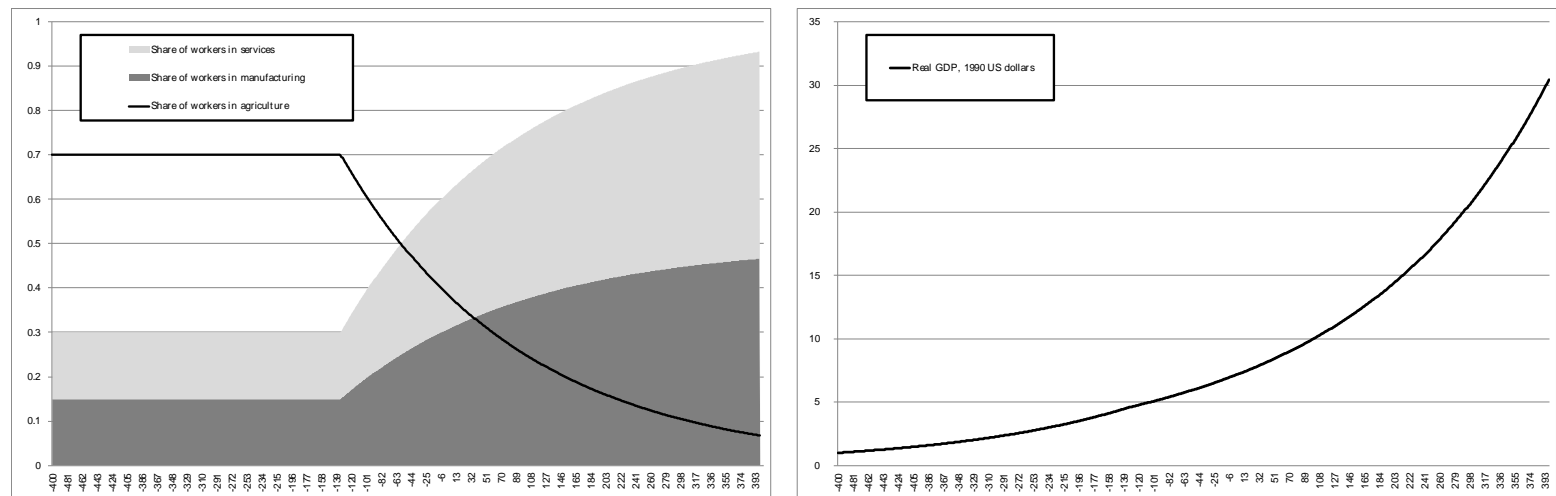

Fig. 15 and 16. Structural change (right) and GDP (left) of the "Roman economy ." 